\title{
Tantalum nitride for photocatalytic water splitting: concept and applications
}

\author{
Ela Nurlaela ${ }^{1} \cdot$ Ahmed Ziani $^{1} \cdot$ Kazuhiro Takanabe $^{1}$ (D)
}

Received: 19 August 2016/ Accepted: 20 September 2016/Published online: 12 October 2016

(C) The Author(s) 2016. This article is published with open access at Springerlink.com

\begin{abstract}
Along with many other solar energy conversion processes, research on photocatalytic water splitting to generate hydrogen and oxygen has experienced rapid major development over the past years. Developing an efficient visible-light-responsive photocatalyst has been one of the targets of such research efforts. In this regard, nitride materials, particularly $\mathrm{Ta}_{3} \mathrm{~N}_{5}$, have been the subject of investigation due to their promising properties. This review focuses on the fundamental parameters involved in the photocatalytic processes targeting overall water splitting using $\mathrm{Ta}_{3} \mathrm{~N}_{5}$ as a model photocatalyst. The discussion primarily focuses on relevant parameters that are involved in photon absorption, exciton separation, carrier diffusion, carrier transport, catalytic efficiency, and mass transfer of the reactants. An overview of collaborative experimental and theoretical approaches to achieve efficient photocatalytic water splitting using $\mathrm{Ta}_{3} \mathrm{~N}_{5}$ is discussed.
\end{abstract}

Keywords $\mathrm{Ta}_{3} \mathrm{~N}_{5} \cdot$ Water splitting $\cdot$ Photocatalysis · Crystal structure $\cdot$ Optoelectronic properties $\cdot$ Kinetics . Carrier dynamic $\cdot$ Interface $\cdot$ Oxygen evolution reaction

\section{Introduction}

The development of new clean and inexpensive energy resources as an alternative to conventional fossil fuel energy is a crucial challenge for the scientific community.

Kazuhiro Takanabe

kazuhiro.takanabe@kaust.edu.sa

1 KAUST Catalysis Center and Physical Sciences and Engineering Division (PSE), King Abdullah University of Science and Technology (KAUST), 4700 KAUST, Thuwal 23955-6900, Saudi Arabia
Solar $\mathrm{H}_{2} \mathrm{O}$ splitting is one of the most innovative solutions that have emerged over the past years [1-8]. $\mathrm{H}_{2}$ production can currently be achieved through an artificial photosynthetic way, in the UV domain, using broad bandgap photocatalyst materials such as $\mathrm{TiO}_{2}$ [9] or using photoactive oxides such as $\alpha-\mathrm{Fe}_{2} \mathrm{O}_{3}, \mathrm{WO}_{3}$ or $\mathrm{BiVO}_{4}$ under visible light irradiation (1.7-2.8 eV) [10-15]. However, these types of materials are effective only for half of the reaction (water oxidation). For overall water splitting, there is a limited choice of photocatalysts, such as $\mathrm{Ta}_{3} \mathrm{~N}_{5}, \mathrm{TaON}$, or some material from the family of oxynitride perovskites [16-24]. Achieving one step overall water splitting with one single photocatalyst presents a practical way in term of engineering design of the reactions. The simplicity of using powder semiconductor photocatalysis makes this technique economically feasible for its scalability and capital cost. Thanks to its extended visible absorption $(600 \mathrm{~nm})$ and its ability for the redox reaction, $\mathrm{Ta}_{3} \mathrm{~N}_{5}$ is an attractive photocatalyst that can theoretically achieve a solar energy to hydrogen conversion efficiency of $\sim 17 \%$. Many studies have addressed improving the photocurrent at the potential for water oxidation [20-24]. A significant photocurrent can be achieved by increasing the structuration of the photocatalyst and using a high-performance cocatalyst, but understanding the intrinsic properties of $\mathrm{Ta}_{3} \mathrm{~N}_{5}$ for obtaining a significant improvement in the global photoelectrocatalytic reaction is still a challenge. Knowledge of the material's intrinsic properties can help to improve the photocatalytic performance.

\section{Photocatalytic water splitting mechanism}

The basic principle of photocatalytic water splitting is schematically depicted in Fig. 1. The reaction begins when the photocatalyst absorbs light with a photon energy 
Fig. 1 Schematic of processes involved in photocatalytic water splitting. The steps involved in the photocatalysis for water splitting process are presented in the scheme: 1 photon absorption, 2 exciton separation, 3 carrier diffusion, 4 carrier transport, 5 catalytic efficiency, and 6 mass transfer of reactants

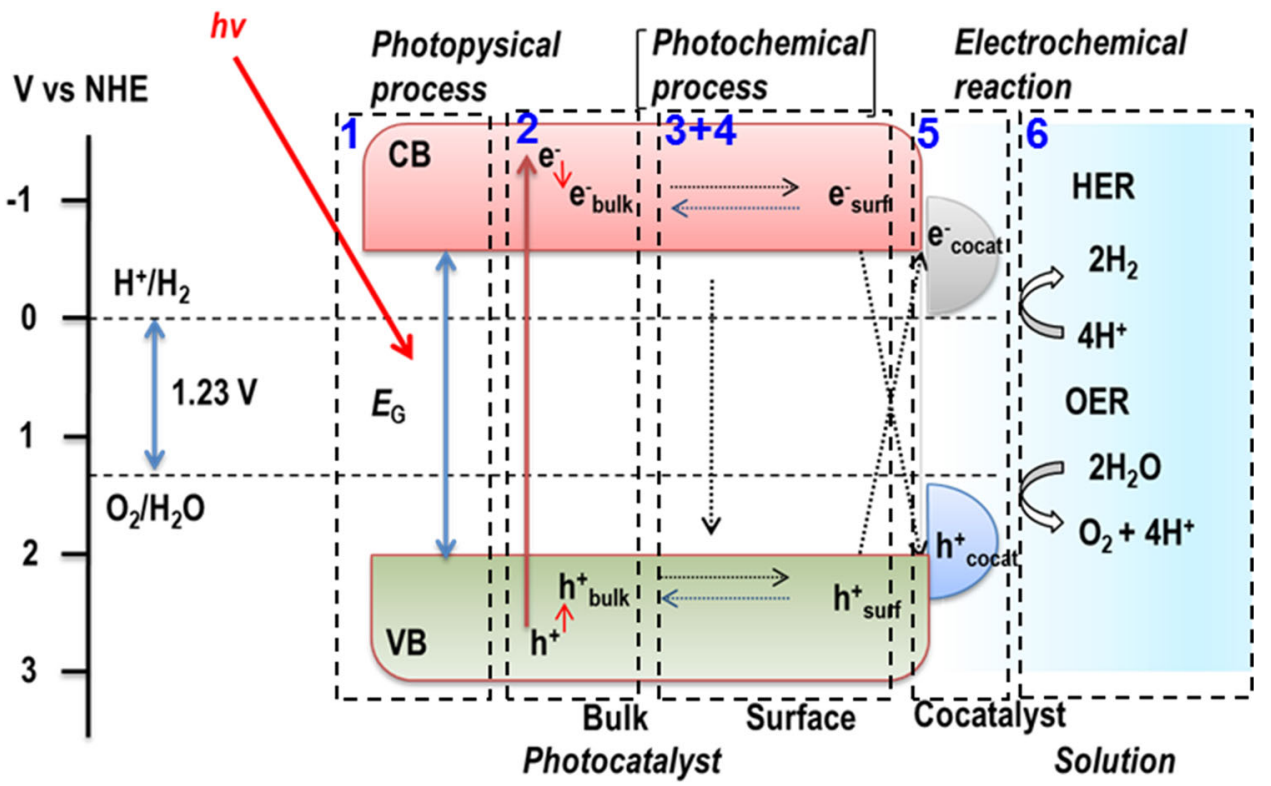

that is higher than its bandgap [7, 8, 18, 25-28]. This process initiates electron excitation from the valence band (VB) to the conduction band (CB), simultaneously leaving a hole in the valence band. This initiation proceeds in a very short time (at the femtosecond scale), followed by relaxation of the hole to the bottom of the $\mathrm{CB}$ and to the top of the VB, respectively, on a similar time scale. Furthermore, the photogenerated charges will undergo an electrochemical reaction on the surface of the photocatalyst when the charges successfully migrate from the bulk to the surface (i.e., no recombination reaction). On the surface of the photocatalyst, the photogenerated electron and hole undergo water reduction and oxidation reactions, respectively. However, to facilitate (and accelerate) these reactions, another catalytic active site (cocatalyst) is introduced onto the surface of the photocatalyst. The presence of an efficient electrocatalyst as a cocatalyst is indispensable because each photon in visible light possesses a limited overpotential for water splitting. In addition, the cocatalyst will preferentially accommodate electrons (hydrogen evolution site) or holes (oxygen evolution site), preventing recombination reactions on the surface [7, 8, 18, 25-28].

From the mechanism for photocatalytic water splitting, it is clear that this reaction involves complex photophysical and chemical processes on different time scales. Our recent review addressed the fundamental parameters involved in photocatalytic overall water splitting [26]. The steps involved in the photocatalysis for water splitting are divided into the following six processes: (1) photon absorption, (2) exciton separation, (3) carrier diffusion, (4) carrier transport, (5) catalytic efficiency, and (6) mass transfer of reactants. All steps are illustrated in Fig. 1.
The current review aims to describe the relevant parameters related to the six processes mentioned above using $\mathrm{Ta}_{3} \mathrm{~N}_{5}$ as a model photocatalyst. Some physicochemical properties, such as electronic structure, interface development, and electrocatalytic properties, will be described and correlated to achieve a comprehensive understanding of the complex sequential processes of overall water splitting.

\section{Why $\mathrm{Ta}_{3} \mathrm{~N}_{5}$ ?}

For a semiconductor to be considered a good material for photocatalytic water splitting, there are several general requirements. First, to utilize visible light, it needs to have a low bandgap energy $[7,8,18,25-31]$. A photocatalyst with a bandgap energy of approximately $2.1 \mathrm{eV}$, corresponding to a wavelength of $600 \mathrm{~nm}$, is sufficient for achieving the targeted efficiency. The second requirement is that the photocatalyst band positions have to straddle the water redox potential $\left(\mathrm{E}_{\mathrm{CB}}>0\right.$ vs. RHE, $\mathrm{E}_{\mathrm{VB}}<1.23$ vs. RHE) $[7,8,18,25-31]$. Next, the photocatalyst needs to have excellent stability under the photocatalytic reaction conditions, under illumination and in the dark [7, 8, 18, 25-31]. Some potential low bandgap energy photocatalysts, such as $\mathrm{CdS}$ and $\mathrm{CdSe}$, fulfill the first requirement and are very active for hydrogen evolution. However, these photocatalysts suffer from photocorrosion or self-oxidation due to their valence band positions, which lie more negative than the water oxidation potential [32-36]. $\mathrm{WO}_{3}$, on the other hand, is very good for oxygen evolution, but its $\mathrm{CB}$ position lies more positive than the water reduction potential $[37,38]$. Hence, compared to photoelectrochemical (PEC) systems, a single photocatalyst system has fewer choices of existing 
photocatalysts. The fourth requirement is that the semiconductor should possess a high catalytic activity toward the oxidation or reduction of water. Finally, the semiconductor must be economically viable. Considering the scalability of the powder photocatalyst system, the photocatalyst must therefore be composed of inexpensive, abundant materials and have a largely scalable synthesis.

Studies on finding suitable and effective photocatalysts to fulfill all the aforementioned requirements have been conducted using various methods. Investigations have mainly focused on reducing the bandgap of the photocatalyst while maintaining its band position relative to the $\mathrm{H}^{+/} \mathrm{H}_{2}$ and $\mathrm{O}_{2} / \mathrm{H}_{2} \mathrm{O}$ redox potentials. The successful synthesis of a visible-light-responsive photocatalyst was demonstrated by the formation of (oxy)nitrides [19-24, 39-50]. Particular interest has been focused on $\mathrm{Ta}_{3} \mathrm{~N}_{5}$ due to its absorption spectrum that can go up to $600 \mathrm{~nm}$ : a target for achieving efficient photocatalytic water splitting. It has been reported that $\mathrm{Ta}_{3} \mathrm{~N}_{5}$ can generate $\mathrm{H}_{2}$ or $\mathrm{O}_{2}$ from water under visible light in the presence of suitable sacrificial reagents [19, 39-47].

Despite considerable studies as a photocatalyst for many years, information on $\mathrm{Ta}_{3} \mathrm{~N}_{5}$ is still lacking regarding its thorough characterization to understand its underlying physical and chemical properties. Theoretical studies on this material are also limited. This review addresses the global picture of photocatalytic reactions using $\mathrm{Ta}_{3} \mathrm{~N}_{5}$ as a model photocatalyst. This material was selected for two reasons. First, the initially reported photocatalytic activities were promising. Second, prior to the start of the work presented in this review, there were conflicting reports on the performance levels of different $\mathrm{Ta}_{3} \mathrm{~N}_{5}$ materials, i.e., there was limited understanding of the factors that affect its photocatalytic performance.

\section{Different methods for $\operatorname{Ta}_{3} \mathrm{~N}_{5}$ synthesis}

$\mathrm{Ta}_{3} \mathrm{~N}_{5}$ is generally synthesized via the direct nitridation of crystalline tantalum oxide $\left(\mathrm{Ta}_{2} \mathrm{O}_{5}\right)$ at high temperatures in the presence of $\mathrm{NH}_{3}$ gas as a nitrogen source. The nitridation of tantalum oxide in a $\mathrm{NH}_{3}$ flow proceeds in a complex manner, where the solid-state diffusion of anion replacements $\left(\mathrm{N}^{3-}\right.$ vs. $\left.\mathrm{O}^{2-}\right)$ occurs while gaseous $\mathrm{NH}_{3}$ decomposes to nitrogen and hydrogen at high temperatures typically between 750 and $1150{ }^{\circ} \mathrm{C}$ [44, 51-54]. The process of anion diffusion requires the substitution of three oxygen atoms with two nitrogen atoms to maintain a high oxidation state of the $\mathrm{Ta}^{0}$ electronic configuration $\left(\mathrm{Ta}^{5+}\right)$. Depending on the amount of $\mathrm{Ta}_{2} \mathrm{O}_{5}$, the $\mathrm{NH}_{3}$ flow rate and temperature are varied, typically in the range of $100-200 \mathrm{~mL} \mathrm{~min}^{-1}$ and $800-900{ }^{\circ} \mathrm{C}$, respectively. This method generally produces sub-micrometer scale $(\sim 50-100 \mathrm{~nm}) \mathrm{Ta}_{3} \mathrm{~N}_{5}$ (Fig. 2a) with a low surface area $\left(\sim 10 \mathrm{~m}^{2} \mathrm{~g}^{-1}\right)$. $\mathrm{Ta}_{3} \mathrm{~N}_{5}$ powder has also been synthesized from amorphous $\mathrm{Ta}_{2} \mathrm{O}_{5}$, as reported by Henderson and Hector [55]. Using $\mathrm{NH}_{3}$ gas between 680 and $900{ }^{\circ} \mathrm{C}, \mathrm{Ta}_{3} \mathrm{~N}_{5}$ with a crystal size of $20-30 \mathrm{~nm}$ was formed.
Fig. 2 SEM images of powder $\mathrm{Ta}_{3} \mathrm{~N}_{5}$ synthesized with different method: a direct nitridation of $\mathrm{Ta}_{2} \mathrm{O}_{5}$, adapted from [44] with permission from the PCCP Owner Societies, b decomposition using mesoporous $\mathrm{g}-\mathrm{C}_{3} \mathrm{~N}_{4}$ template, adapted from [46] by permission of John Wiley \& Sons Inc, $\mathbf{c}$ nitridation of $\mathrm{Na}_{2} \mathrm{CO}_{3}$-pretreated $\mathrm{Ta}_{2} \mathrm{O}_{5}$, adapted with permission from [42] Copyright (2012)

American Chemical Society, and d nanorod $\mathrm{Ba}-\mathrm{Ta}_{3} \mathrm{~N}_{5}$ film synthesized by nitridation of $\mathrm{Ta}_{2} \mathrm{O}_{5}$ nanorods, adapted from [21] Copyright 2013, Nature Publishing Group
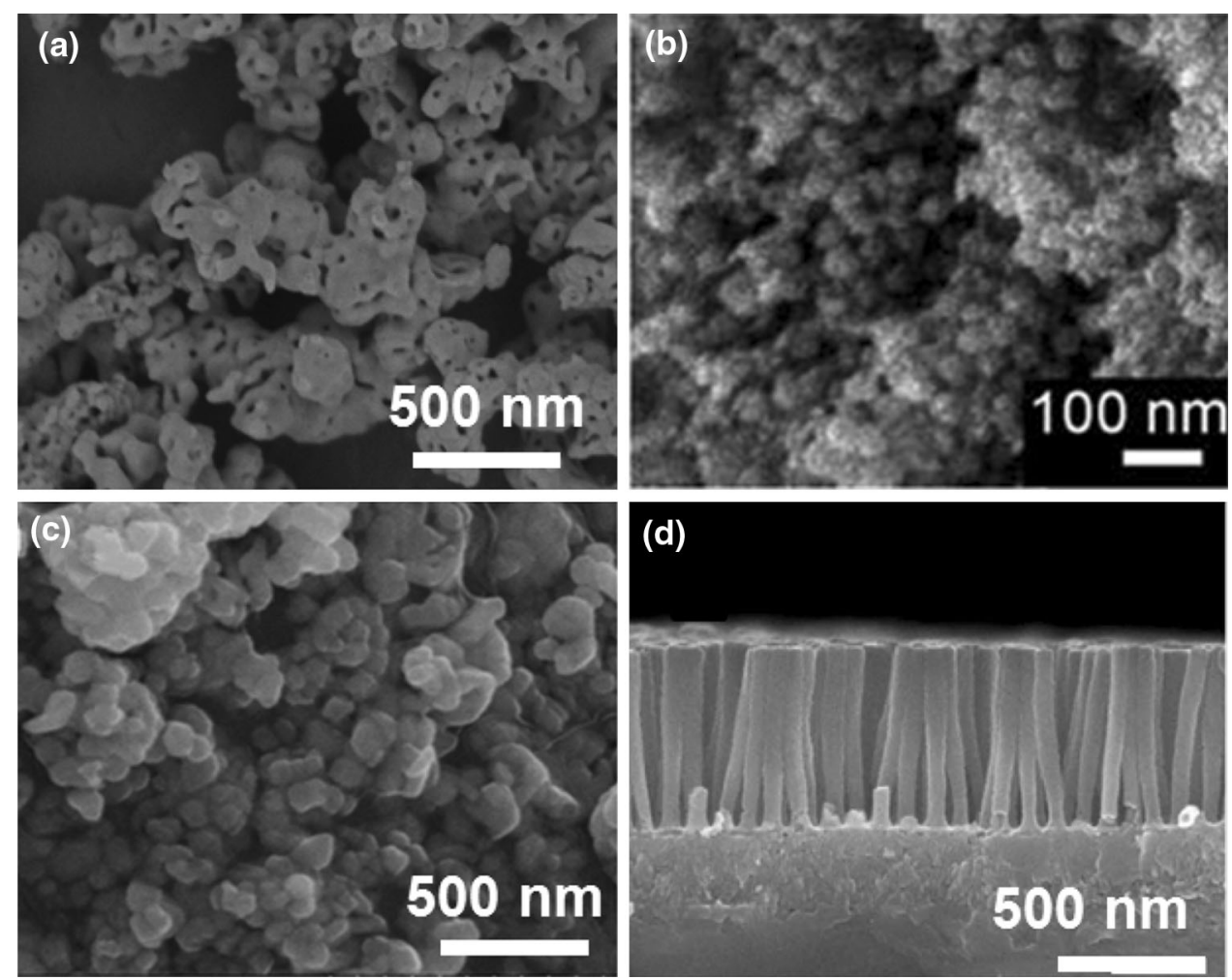
Direct nitridation generally produces $\mathrm{Ta}_{3} \mathrm{~N}_{5}$ with good photocatalytic activity toward oxygen evolution but low activity for hydrogen evolution, approximately one order of magnitude lower than that for oxygen evolution [19, 39-47]. The resulting $\mathrm{Ta}_{3} \mathrm{~N}_{5}$ generally contains some anion defects, as observed from its absorption spectrum after the band edge absorption $(\sim 710 \mathrm{~nm})$, which is associated with its low photocatalytic performance due to the recombination reaction of photogenerated electrons-holes [43]. In addition, this method resulted in agglomerated $\mathrm{Ta}_{3} \mathrm{~N}_{5}$ with a very low surface area [19, 39-47]. To overcome these problems, several attempts to improve the synthesis method of $\mathrm{Ta}_{3} \mathrm{~N}_{5}$ have been pursued in various ways.

To improve the surface area and obtain a uniform size distribution, nanoparticle (NP) $\mathrm{Ta}_{3} \mathrm{~N}_{5}$ has been successfully synthesized using mesoporous graphitic carbon nitride $\left(\mathrm{mpg}-\mathrm{C}_{3} \mathrm{~N}_{4}\right)$ as a decomposable and reactive template $[45,46]$. The particle size of $\mathrm{Ta}_{3} \mathrm{~N}_{5}$ is controlled to sizes as small as approximately $7 \mathrm{~nm}$ by controlling (Fig. 2b) the pore size of the mpg- $\mathrm{C}_{3} \mathrm{~N}_{4}$ template, and its surface area can reach $60 \mathrm{~m}^{2} \mathrm{~g}^{-1}$. The resulting $\mathrm{Ta}_{3} \mathrm{~N}_{5}$ NPs exhibits improved photocatalytic activity for $\mathrm{H}_{2}$ evolution in the presence of methanol as a sacrificial reagent. The size of semiconductor particles is believed to affect their photocatalytic activity by reducing the distance that the excited electrons and holes must travel to reach the active surface sites. Moreover, the size has also been hypothesized to affect the space-charge layer and band bending that govern the photocatalytic activity [45].

Improved photocatalytic hydrogen evolution was reported on $\mathrm{Ta}_{3} \mathrm{~N}_{5}$ synthesized using a sol-gel method. In this method, $\mathrm{Ta}_{2} \mathrm{O}_{5}$ was first grown on the surface of $\mathrm{SiO}_{2}$ spheres with a diameter of $\sim 550 \mathrm{~nm}$ and subsequently subjected to nitridation [47]. The final $\mathrm{Ta}_{3} \mathrm{~N}_{5} / \mathrm{SiO}_{2}$ sample exhibited a uniform size distribution with high crystallinity and a coreshell structure with a narrow size distribution without aggregation. The photocatalytic activity of the $\mathrm{Ta}_{3} \mathrm{~N}_{5} / \mathrm{SiO}_{2}$ samples toward hydrogen evolution was considerably higher than that of $\mathrm{Ta}_{3} \mathrm{~N}_{5}$ synthesized via the conventional nitridation of commercial $\mathrm{Ta}_{2} \mathrm{O}_{5}$. Interestingly, when no $\mathrm{SiO}_{2}$ was used, the photocatalytic hydrogen evolution of sol-gel $\mathrm{Ta}_{3} \mathrm{~N}_{5}$ was relatively comparable to that of $\mathrm{Ta}_{3} \mathrm{~N}_{5} / \mathrm{SiO}_{2}$. Hence, attributing the improvement in photocatalytic activity toward hydrogen evolution to only the smaller particle size and higher surface area is questionable. Note that light scattering by $\mathrm{SiO}_{2}$ in such a way to improve the absorption of light by $\mathrm{Ta}_{3} \mathrm{~N}_{5}$ may occur. A simple physical mixture of $\mathrm{SiO}_{2}$ and $\mathrm{Ta}_{3} \mathrm{~N}_{5}$ did not improve photocatalytic performance; thus, an additional understanding of this type of supported photocatalyst is required.

Through a simple modification of the synthesis with an alkali metal salt, an improved photocatalytic oxygen evolution has been achieved on $\mathrm{Ta}_{3} \mathrm{~N}_{5}$ [42]. In this method, the
$\mathrm{Ta}_{2} \mathrm{O}_{5}$ precursor was first modified with an alkali metal salt (i.e., $\mathrm{Na}_{2} \mathrm{CO}_{3}$ ) prior to nitridation. This alkali metal salt produces a molten salt state at high synthesis temperatures (flux). The presence of the alkali metal salt improved the activity of $\mathrm{Ta}_{3} \mathrm{~N}_{5}$ by affecting the crystal growth, which further led to higher crystallinity and a smaller particle size (Fig. 2c). Although low valence cation substitution may reduce the number of reduced Ta species by charge compensation, the enhanced physicochemical properties of $\mathrm{Na}$ doped $\mathrm{Ta}_{3} \mathrm{~N}_{5}$ and their relationship to higher photocatalytic activity remain unclear.

Quantum confinement in semiconductor nanoparticles (NPs) is believed to be capable of tuning the redox properties of the material if the size of the NPs becomes smaller than the exciton radius of an electron-hole pair [56, 57]. The synthesis of colloidal $\mathrm{Ta}_{3} \mathrm{~N}_{5}$ NPs has been achieved by injecting a variety of reactive tantalum and nitrogen precursors into hot coordinating solvents under an inert atmosphere [58]. Through the use of different organic solvents and reaction times, the size of the NPs can be tuned in the range from 2 to $23 \mathrm{~nm}$. A change in the bandgap energy of colloidal $\mathrm{Ta}_{3} \mathrm{~N}_{5}$ NPs was observed from the absorption spectrum, where colloidal NPs have absorption onsets greater than that of the bulk powders by $\sim 0.3 \mathrm{eV}$. Despite the successful formation of very small $\mathrm{Ta}_{3} \mathrm{~N}_{5}$ particles, this method suffers from very low $\mathrm{Ta}_{3} \mathrm{~N}_{5}$ yields along with problems of $\mathrm{Ta}_{3} \mathrm{~N}_{5}$ oxidation, which suggest that this method is not likely to be effective for the large-scale production of metal nitride nanoparticles [58].

The controllable synthesis of $\mathrm{Ta}_{3} \mathrm{~N}_{5}$ with a tailored chemical composition and size has been attempted using urea as the $\mathrm{N}$ source rather than $\mathrm{NH}_{3}$ gas [59]. By varying the urea/Ta ratio in the precursor gel, both $\mathrm{TaON}$ and $\mathrm{Ta}_{3} \mathrm{~N}_{5}$ NPs with defined structures and sizes can be achieved. Assisted by $\mathrm{SiO}_{2}$, the production of $\mathrm{TaON}$ and $\mathrm{Ta}_{3} \mathrm{~N}_{5}$ NPs with tailored compositions was achieved through the calcination of Ta-urea gels with suitable urea/Ta ratios (RU/Ta). In this method, urea is first converted into carbon-nitride $\left(\mathrm{CN}_{\mathrm{x}}\right)$ species on the surface of $\mathrm{SiO}_{2}$ at mild temperatures, which further acts as a slow-release $\mathrm{N}$ source for controlled nitridation.

Regarding the synthesis of $\mathrm{Ta}_{3} \mathrm{~N}_{5}$ electrodes, the majority of the films were obtained by Ta foil post-calcination [48, 49, 60], Ta anodization (Fig. 2d) [24, 61], or by sputtering $[41,62]$. In our previous work on $\mathrm{Ta}_{3} \mathrm{~N}_{5}$, we reported thin films with different thicknesses fabricated in a controlled manner using reactive direct current sputtering followed by optimal annealing and nitridation. The preparation of such $\mathrm{Ta}_{3} \mathrm{~N}_{5}$ photoanodes in the form of dense thin films is a useful approach for obtaining a high crystalline quality that may effectively increase the efficiency of the process and the chemical stability of the PEC system. The thin film configuration also allows for thorough characterization of the photophysical properties of the 
material, such as the $\mathrm{Ta}_{3} \mathrm{~N}_{5}$ properties and photocatalytic performance.

\section{Structural and optoelectronic properties of $\operatorname{Ta}_{3} \mathrm{~N}_{5}$ : detailed experiments and theoretical calculations}

The crystal and electronic structures are two factors that primarily determine the absorption properties of a powder semiconductor [26]. The electronic properties of a semiconductor define the bandgap and band positions, the nature of direct and indirect light absorption, and the absorption coefficient. Essentially, the main effect resulting from direct and indirect bandgaps is the absorption coefficient, where a direct bandgap provides a high absorption coefficient and an indirect bandgap leads to a lower absorption coefficient. An indirect transition involves both a photon and a phonon because the band edges of the conduction and valence bands are widely separated in $\mathrm{k}$-space. The crystal orbitals at the top of the valence band and at the bottom of the conduction band have the same wave vector in a direct bandgap solid but different wave vectors in an indirect bandgap material.

\section{Crystal structure}

The crystal structure of $\mathrm{Ta}_{3} \mathrm{~N}_{5}$ was first reported by Brese and O'Keeffe using time-of-flight neutron diffraction [63]. $\mathrm{Ta}_{3} \mathrm{~N}_{5}$ has an orthorhombic structure composed of irregular octahedra of $\mathrm{N}$ atoms with Ta atoms in the center. Two nitrogen atoms have four Ta atoms as the nearest neighbors, while another single nitrogen atom is coordinated to three Ta atoms. The Ta-N distances range from 1.96 to $2.24 \AA$ and are similar to those in $\mathrm{TaON}$.

The crystal structure of $\mathrm{Ta}_{3} \mathrm{~N}_{5}$ based on our theoretical calculations is shown in Fig. 3a. $\mathrm{Ta}_{3} \mathrm{~N}_{5}$ has an (a)

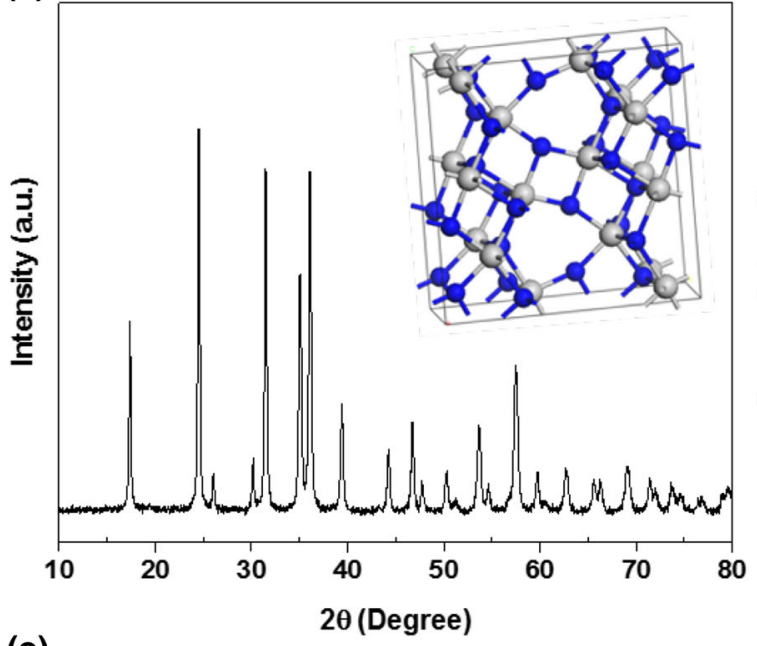

(c)

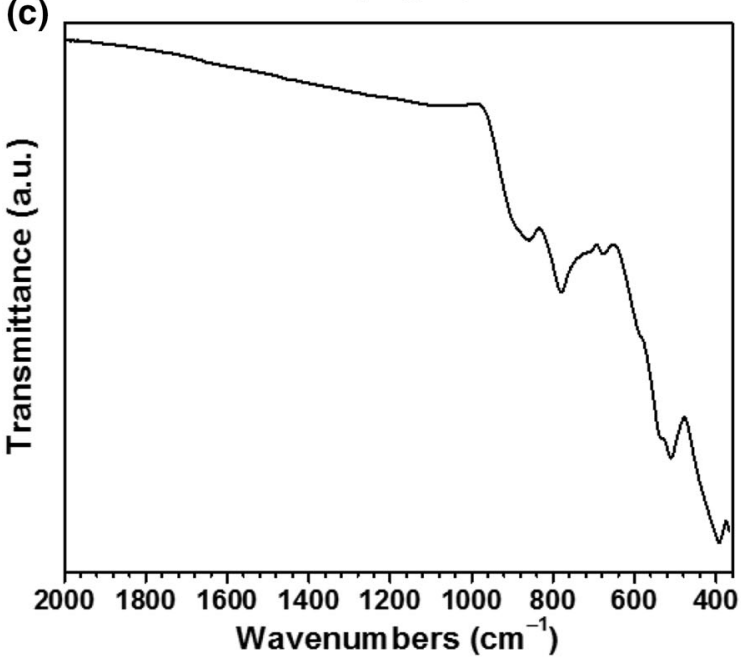

(b)

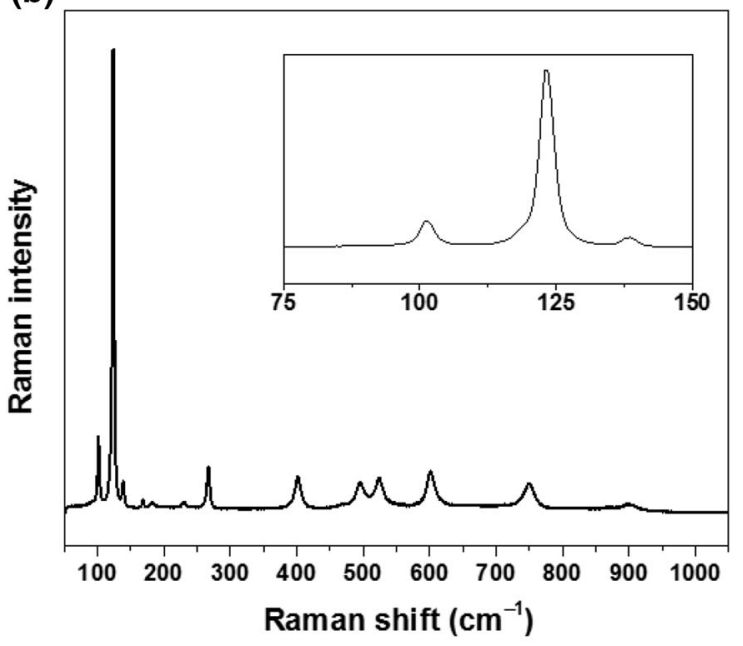

Fig. 3 a XRD pattern and crystal structure (inset), b Raman spectra, and c IR spectra of $\mathrm{Ta}_{3} \mathrm{~N}_{5}$ obtained from nitridation of $\mathrm{Ta}_{2} \mathrm{O}_{5}$ by $15 \mathrm{~h}$ in $\mathrm{NH}_{3}$ gas at $900{ }^{\circ} \mathrm{C}$. Color legend for crystal structure: Ta in gray and $\mathrm{N}$ in blue. All figures are adapted from [64] by permission of Elsevier 
orthorhombic structure with space group $\mathrm{Cmcm}$, which is composed of edge-sharing irregular $\mathrm{TaN}_{6}$ octahedra. Each Ta is coordinated by two $\mathrm{N}$ (that are threefold coordinated) and four $\mathrm{N}$ (that are fourfold coordinated) with $\mathrm{Ta}-\mathrm{N}$ bond lengths ranging from 2.0 to $2.23 \AA$.

In our previous work, $\mathrm{Ta}_{3} \mathrm{~N}_{5}$ powder was synthesized through the direct nitridation of crystalline $\mathrm{Ta}_{2} \mathrm{O}_{5}$ under a $\mathrm{NH}_{3}$ flow at high temperature $[43,44,64]$. XRD characterization was performed to investigate the crystal structures of the synthesized materials. The successive nitridation completely changed the crystal structures of the products from the initial $\beta-\mathrm{Ta}_{2} \mathrm{O}_{5}$ to monoclinic $\beta$-TaON and then to orthorhombic $\mathrm{Ta}_{3} \mathrm{~N}_{5}$, which is consistent with the literature $[39,40,44]$. The XRD patterns of samples heated at 800 and $900{ }^{\circ} \mathrm{C}$ for $15 \mathrm{~h}$ under different $\mathrm{NH}_{3}$ flow rates were compared. For both temperatures, changing the flow rate clearly changed the $\mathrm{TaON}$ and $\mathrm{Ta}_{3} \mathrm{~N}_{5}$ concentrations. At $900{ }^{\circ} \mathrm{C}$, a mixture of oxynitride $(\mathrm{TaON})$ and nitride $\left(\mathrm{Ta}_{3} \mathrm{~N}_{5}\right)$ material phases was observed for lower flow rates (i.e., 50-100 $\mathrm{mL} \mathrm{min}^{-1} \mathrm{NH}_{3}$ ), whereas a higher amount of the $\mathrm{Ta}_{3} \mathrm{~N}_{5}$ phase was observed at higher flow rates. Complete transformation of $\mathrm{Ta}_{2} \mathrm{O}_{5}$ to $\mathrm{Ta}_{3} \mathrm{~N}_{5}$ was achieved after prolonged nitridation at $900{ }^{\circ} \mathrm{C}$ for $15 \mathrm{~h}$ under a $200 \mathrm{~mL} \mathrm{~min}^{-1}$ $\mathrm{NH}_{3}$ flow. No remaining $\mathrm{Ta}_{2} \mathrm{O}_{5}$ or partially nitrided phase (e.g., $\beta$-TaON) was detected, as can be seen from XRD pattern presented in Fig. 3a. The resulting $\mathrm{Ta}_{3} \mathrm{~N}_{5}$ has an orthorhombic crystal structure (ICSD card No. 1005006) with $\mathrm{Cmcm}$ space group. Similarly, for samples nitrided at $800{ }^{\circ} \mathrm{C}$, the amount of the $\mathrm{Ta}_{3} \mathrm{~N}_{5}$ phase increased with increasing $\mathrm{NH}_{3}$ flow rate. However, at $800{ }^{\circ} \mathrm{C}$, higher flow rates up to $500 \mathrm{~cm}^{3} \mathrm{~min}^{-1}$ did not change the entire $\mathrm{Ta}_{2} \mathrm{O}_{5}$ precursor into the pure $\mathrm{Ta}_{3} \mathrm{~N}_{5}$ phase. Some remaining $\mathrm{TaON}$ ( $\sim 8 \mathrm{wt} \%$ ) phase was still observed. It is suggested that competitive substitution of $\mathrm{O}$ with $\mathrm{N}$ between the $\mathrm{NH}_{3}$ feed and $\mathrm{H}_{2} \mathrm{O}$ occurred, where the chemical potential of oxygen kinetically determines these pseudo-thermodynamically stable phase diagrams [44].

The fact that a mixture of $\mathrm{TaON}$ and $\mathrm{Ta}_{3} \mathrm{~N}_{5}$ always forms at $800{ }^{\circ} \mathrm{C}$ regardless of the flow rates under our conditions suggested that, during nitridation, the oxide was first transformed into oxynitride prior to nitride. This finding is in good agreement with reports in the literature, which state that $\mathrm{TaON}$ is the intermediate phase in the formation of $\mathrm{Ta}_{3} \mathrm{~N}_{5}$ from the $\mathrm{Ta}_{2} \mathrm{O}_{5}$ precursor [39, 40, 51, 64]. This also implies that the nitridation proceeds via the successive transformation of $\mathrm{Ta}_{2} \mathrm{O}_{5} \mathrm{TaON}$ $\mathrm{Ta}_{3} \mathrm{~N}_{5}$, where a continuous dehydration reaction occurs. In this study, no concrete evidence could be found that the transformation of $\mathrm{Ta}_{2} \mathrm{O}_{5}$ to $\mathrm{Ta}_{3} \mathrm{~N}_{5}$ is initially triggered by the incorporation of $\mathrm{N}$ atoms into the $\mathrm{Ta}_{2} \mathrm{O}_{5}$ lattice to form $\mathrm{N}$-doped $\mathrm{Ta}_{2} \mathrm{O}_{5}$, as observed by Dabirian et al. where in situ XRD was utilized to follow the nitridation of $\mathrm{Ta}_{2} \mathrm{O}_{5}$ films [52].
The crystallite sizes for the synthesized samples and the lattice parameters were obtained from Rietveld analysis. The lattice parameters of $\mathrm{Ta}_{3} \mathrm{~N}_{5}$ obtained from the XRD measurements and calculations are listed in Table 1. The calculated lattice parameters for $\mathrm{Ta}_{3} \mathrm{~N}_{5}$ at the DFT/PBE level of theory are found to be in excellent agreement with the experimental data. The $\mathrm{Ta}_{3} \mathrm{~N}_{5}$ samples synthesized at different temperatures with similar $\mathrm{NH}_{3}$ flow rates and samples synthesized at $800{ }^{\circ} \mathrm{C}$ with different $\mathrm{NH}_{3}$ flow rates did not exhibit any significant change in lattice parameters. Hence, the incorporation of $\mathrm{N}$ into $\mathrm{Ta}_{2} \mathrm{O}_{5}$ (i.e., the formation of doped- $\mathrm{Ta}_{2} \mathrm{O}_{5}$ ) is unlikely, as observed for the synthesis of $\mathrm{Ta}_{3} \mathrm{~N}_{5}$ films [52]. In addition, the lattice parameters are also compared with those reported in the literature.

\section{Lattice dynamics}

Prior to our report, there was only limited literature on the lattice dynamics of $\mathrm{Ta}_{3} \mathrm{~N}_{5}$ [43]. In our recent paper, detailed theoretical calculations and experimental results of $\mathrm{Ta}_{3} \mathrm{~N}_{5}$ were explored [64]. Orthorhombic $\mathrm{Ta}_{3} \mathrm{~N}_{5}$ with space group $\mathrm{Cmcm}$ is predicted to have a total of 24 Ramanactive modes, $8 \mathrm{~A}_{\mathrm{g}}+16 \mathrm{~B}_{\mathrm{g}}$, and 21 IR-active modes, $3 \mathrm{~A}_{\mathrm{u}}+18 \mathrm{~B}_{\mathrm{u}}$. However, some frequencies predicted by the DFPT/PBE method have not been experimentally observed, most likely due to the low scattering cross-section of these modes and because the peaks are consequently hidden in the background. On the other hand, the experimental Raman spectrum exhibits 19 active modes and a few modes that are not predicted by the theoretical calculation. Nevertheless, the model generally reproduces the experimental data accurately, particularly at low wavenumbers.

The experimentally measured Raman spectra (Fig. 3b) show the most intense peaks at low wavenumbers, 102, $123,138,152,168,230,266,400$, and $495 \mathrm{~cm}^{-1}$, which are very well matched with the theoretically calculated peaks within 3-4 $\mathrm{cm}^{-1}$. These modes are assigned to $B_{g}$, $\mathrm{B}_{\mathrm{g}}, \mathrm{A}_{\mathrm{g}}, \mathrm{B}_{\mathrm{g}}, \mathrm{B}_{\mathrm{g}}, \mathrm{A}_{\mathrm{g}}, \mathrm{A}_{\mathrm{g}}, \mathrm{A}_{\mathrm{g}}$, and $\mathrm{B}_{\mathrm{g}}$, respectively. However, at higher wavenumbers, the agreement is less evident. The experimental peaks located at 524 and $601 \mathrm{~cm}^{-1}$, which are both assigned to $A_{g}$ modes, are still quite well reproduced by the computed values within $5 \mathrm{~cm}^{-1}$, whereas for the peaks at 749, 869, and $900 \mathrm{~cm}^{-1}$, which are assigned to the $\mathrm{B}_{\mathrm{g}}, \mathrm{B}_{\mathrm{g}}$, and $\mathrm{A}_{\mathrm{g}}$ modes, respectively, there is a larger variation in the range of $10 \mathrm{~cm}^{-1}$. This behavior at higher wavenumbers was expected according to several reports in which the low energy part of the experimental spectrum was always better matched by theory than the higher energy part $[71,72]$. Two peaks at 658 and $823 \mathrm{~cm}^{-1}$ were observed experimentally but not predicted by theory. These peaks were broadened and 
Table 1 Comparison of $\mathrm{Ta}_{3} \mathrm{~N}_{5}$ crystal structure obtained from theoretical calculation and experimental measurement

\begin{tabular}{|c|c|c|c|}
\hline Crystal structure & Calculation & Experimental & Method/references \\
\hline \multicolumn{4}{|l|}{ Lattice parameter } \\
\hline $\mathrm{a}, \mathrm{b}, \mathrm{c}(\AA)$ & $3.89,10.25,10.27$ & & DFT-PBE $[44,45,65]$ \\
\hline $\mathrm{a}, \mathrm{b}, \mathrm{c}(\AA)$ & & $3.89,10.22,10.27$ & Powder XRD, Rietveld analysis $[44,45,65]$ \\
\hline $\mathrm{a}, \mathrm{b}, \mathrm{c}(\AA)$ & & $3.89,10.21,10.26$ & Neutron diffraction [64] \\
\hline $\mathrm{a}, \mathrm{b}, \mathrm{c}(\AA)$ & $3.87,10.22,10.26$ & & $\operatorname{PBE}(\mathrm{QE})[68]$ \\
\hline $\mathrm{a}, \mathrm{b}, \mathrm{c}(\AA)$ & $3.90,10.33,10.32$ & & PBE (CRYSTAL) [68] \\
\hline $\mathrm{a}, \mathrm{b}, \mathrm{c}(\AA)$ & $3.85,10.14,10.16$ & & LDA (QE) [69] \\
\hline $\mathrm{a}, \mathrm{b}, \mathrm{c}(\AA)$ & $3.99,10.69,10.69$ & & rev PBE [70] \\
\hline $\mathrm{a}, \mathrm{b}, \mathrm{c}(\AA)$ & $3.87,10.24,10.26$ & & PBE [70] \\
\hline $\mathrm{a}, \mathrm{b}, \mathrm{c}(\AA)$ & $3.91,10.32,10.35$ & & PBE [71] \\
\hline $\mathrm{a}, \mathrm{b}, \mathrm{c}(\AA)$ & $4.00,10.43,10.48$ & & $\mathrm{CGA}+\mathrm{U}[72]$ \\
\hline $\mathrm{a}, \mathrm{b}, \mathrm{c}(\AA)$ & $3.87,10.25,10.27$ & & HSE [71] \\
\hline $\begin{array}{l}\text { a, b, c }(\AA) \\
\text { a, b, c }(\AA)\end{array}$ & & $3.89,10.22,10.28$ & Neutron diffraction [56] \\
\hline \multicolumn{4}{|l|}{ Atom position } \\
\hline Ta1 (4e); x, y, z & $0,0.198,0.250$ & $0,0.197,0.250$ & DFT-PBE and powder XRD, Rietveld analysis [65] \\
\hline Ta2 (8e); x, y, z & $0,0.133,0.559$ & $0,0.134,0.560$ & \\
\hline $\mathrm{N} 1(4 \mathrm{e}) ; \mathrm{x}, \mathrm{y}, \mathrm{z}$ & $0,0.764,0.250$ & $0,0.762,0.250$ & \\
\hline $\mathrm{N} 2(8 \mathrm{e}) ; \mathrm{x}, \mathrm{y}, \mathrm{z}$ & $0,0.046,0.120$ & $0,0.044,0.116$ & \\
\hline $\mathrm{N} 3(8 \mathrm{e}) ; \mathrm{x}, \mathrm{y}, \mathrm{z}$ & $0,0.309,0.073$ & $0,0.304,0.072$ & \\
\hline Ta1 (4c); x, y, z & & $0,0.197,0.250$ & Neutron diffraction [64] \\
\hline Ta2 (8f); x, y, z & & $0,0.135,0.559$ & \\
\hline $\mathrm{N} 1(4 \mathrm{c}) ; \mathrm{x}, \mathrm{y}, \mathrm{z}$ & & $0,0.763,0.250$ & \\
\hline $\mathrm{N} 2(8 \mathrm{f}) ; \mathrm{x}, \mathrm{y}, \mathrm{z}$ & & $0,0.047,0.119$ & \\
\hline $\mathrm{N} 3$ (8f); $\mathrm{x}, \mathrm{y}, \mathrm{z}$ & & $0,0.309,0.074$ & \\
\hline
\end{tabular}

enhanced in resonance conditions using $\lambda_{\mathrm{ex}}=532 \mathrm{~nm}$ $(2.33 \mathrm{eV})$ and $\lambda_{\mathrm{ex}}=473 \mathrm{~nm}(2.62 \mathrm{eV})$, and likely due to LO overtones, were too weak to be observed in nonresonance conditions. In particular, the peak at $823 \mathrm{~cm}^{-1}$ observed with $\lambda_{\mathrm{ex}}=532 \mathrm{~nm}$ might be the second overtone $\left(3 \omega_{\mathrm{Ag}}\right)$ of $\omega_{\mathrm{Ag}}=266 \mathrm{~cm}^{-1}$, and the peak at $523 \mathrm{~cm}^{-1}$, which was not very well matched by the theoretical models, might be the first overtone $2 \omega_{\mathrm{Ag}}$. In addition, these modes might also originate from different localized non-stoichiometries in the crystal that can be activated by one or various excitation wavelengths [44].

In addition to Raman's spectra, we reported calculated and experimentally measured IR spectra (Fig. 3c). There is a good agreement between the theoretical calculations with the experimental frequencies. However, most of the theoretically predicted modes cannot be associated with any experimental peak, probably because they are hidden in the background due to the low intensity. Moreover, a part of the spectrum, namely below $360 \mathrm{~cm}^{-1}$, could not be measured experimentally due to the instrumental limitation.

\section{Absorption coefficient and bandgap energy}

The absorption spectrum of $\mathrm{Ta}_{3} \mathrm{~N}_{5}$ powder is generally expressed from its diffuse reflectance spectrum [26]. Typically, $\mathrm{Ta}_{3} \mathrm{~N}_{5}$ presents absorption from the UV region up to $600 \mathrm{~nm}$, which is attributed to electron transitions from the $\mathrm{N} 2 \mathrm{p}$ orbitals to the empty Ta 5d orbitals [42]. The bandgap energy calculated using a Tauc plot (Fig. 4a, b) yielded values of 2.1 and $2.0 \mathrm{eV}$ for the direct bandgap and indirect bandgap excitations, respectively; these values are in good agreement with previously reported values [18-29].

One interesting feature observed in the absorption spectrum of $\mathrm{Ta}_{3} \mathrm{~N}_{5}$ is the extent of sub-bandgap absorption at approximately $715 \mathrm{~nm}$. The enhanced sub-bandgap absorption at wavelengths greater than $600 \mathrm{~nm}$ has been previously assigned to reduced $\mathrm{Ta}^{5+}$, which is presumably present at the surface of the $\mathrm{Ta}_{3} \mathrm{~N}_{5}$ [62]. In contrast, Dabirian and Van de Krol [73] attributed the enhanced absorption of $\mathrm{Ta}_{3} \mathrm{~N}_{5}$ at wavelengths greater than $600 \mathrm{~nm}$ to its bulk properties rather than to its surface. The highly charged nitrogen vacancy that formed during prolonged 
Fig. 4 Tauc's plots of $\mathrm{Ta}_{3} \mathrm{~N}_{5}$ for $\mathbf{a}$ direct and $\mathbf{b}$ indirect bandgaps. Figures are reproduced from [64] by permission of Elsevier

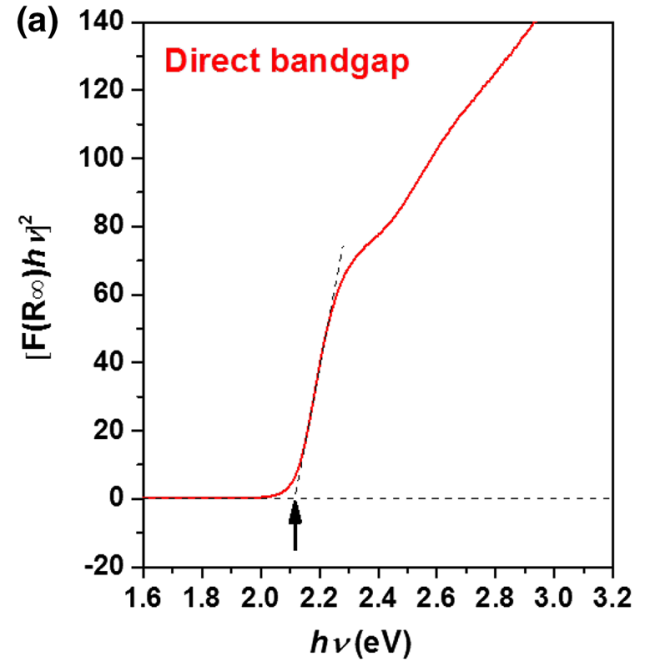

nitridation is a likely candidate for the deep donor state responsible for the absorption feature at wavelengths greater than $600 \mathrm{~nm}$. This assignment was rationalized by the fact that oxygen is always present at the 3-coordinated nitrogen sites in the $\mathrm{Ta}_{3} \mathrm{~N}_{5}$ structure. To elaborate the origin of this sub-bandgap absorption, a theoretical calculation was performed [43]. The $720 \mathrm{~nm}$ sub-bandgap optical absorption of $\mathrm{Ta}_{3} \mathrm{~N}_{5}$ was formed due the appearance of new deep donor metallic states located within the $0.7 \mathrm{eV}$ range just below the original conduction band edge of pure $\mathrm{Ta}_{3} \mathrm{~N}_{5}$, which corresponds to reduced Ta species $\left(\mathrm{Ta}^{3+}\right)$ originating from $\mathrm{O}$ species substituted at $\mathrm{N}$ sites, as in $\mathrm{Ta}_{3} \mathrm{~N}_{4.83} \mathrm{O}_{0.17}$. This finding is in a good agreement with the Raman spectra, where the $\mathrm{Ta}_{3} \mathrm{~N}_{5}$ crystal is most likely nonstoichiometric with oxygen substituted for nitrogen [64]. Indeed, elemental analysis under a control atmosphere always shows the presence of oxygen even though XRD shows a pure phase of $\mathrm{Ta}_{3} \mathrm{~N}_{5}$ [43, 44, 64]. In line with this, our group has systematically investigated the possible structures and found that the experimentally prepared tantalum nitride materials are most likely not stoichiometric but strongly enriched in $\mathrm{O}$, closer to $\left.\left.\mathrm{Ta}_{(3-\mathrm{x}}\right) \mathrm{N}_{(5-5 \mathrm{x}}\right) \mathrm{O}_{5 \mathrm{x}}$ (for $x \geq 0.16$ ) rather than $\mathrm{Ta}_{3} \mathrm{~N}_{5}$ [44].

We can accurately deduce the $\mathrm{Ta}_{3} \mathrm{~N}_{5}$ absorption coefficient from the transmittances and reflectances of different thicknesses of thin films. An absorbance edge of $\sim 600 \mathrm{~nm}$ was observed for all of the films, which is consistent with the reported $2.1 \mathrm{eV}$ bandgap of $\mathrm{Ta}_{3} \mathrm{~N}_{5}$ [30]. As can be seen in Fig. 5a, the absorption coefficient appears to monotonically decrease with increasing wavelengths, and the values are relatively low, starting from $8 \times 10^{5}$ to $1 \times 10^{4} \mathrm{~cm}^{-1}$ in the spectral range relevant to the PEC measurement $(300-600 \mathrm{~nm})$. In addition to absorption coefficient measurements from $\mathrm{Ta}_{3} \mathrm{~N}_{5}$ thin films, we performed theoretical calculations of the absorption coefficient [44, 64]. In agreement with those reported in the literature, in our calculations for pure $\mathrm{Ta}_{3} \mathrm{~N}_{5}$, the density of states (DOS) calculated using the HSE06 functional predicts a bandgap of $2.2 \mathrm{eV}$ (Fig. 5c). The electronic analysis reveals a VB governed by occupied $\mathrm{N} 2 \mathrm{p}$ states and a CB that is primarily composed of empty Ta $5 \mathrm{~d}$ states. Our bandgap of $2.2 \mathrm{eV}$ calculated using HSE06 closely matches the available experimental data. Based on the DOS results, our UV-Visible optical absorption spectrum calculated using DFPT-HSE06 reveals a broad absorption edge extending to $564 \mathrm{~nm}$ (Fig. 5b). The lowest-energy bandgap in this compound involves transitions between $\mathrm{N} 2 \mathrm{p}^{6}$ orbitals and $\mathrm{Ta} 5 \mathrm{~d}^{0}$ orbitals. Similar absorption behavior was exhibited by non-stoichiometric $\mathrm{Ta}_{3} \mathrm{~N}_{5}$ (O-enriched $\mathrm{Ta}_{3} \mathrm{~N}_{5}$ ) materials. The lowest-energy bandgaps in these compounds involve transitions between $\mathrm{N} 2 \mathrm{p}^{6}$ orbitals and Ta $5 \mathrm{~d}^{0}$ orbitals. Their calculated UV-Vis optical absorption coefficient spectra are found to be slightly blue-shifted over pure $\mathrm{Ta}_{3} \mathrm{~N}_{5}$, revealing new absorption onsets at 540, 517, and $497 \mathrm{~nm}$, respectively (Fig. 3b). The top part of the valence band in these compounds is dominated by occupied $\mathrm{N} 2 \mathrm{p}$ states due to the very weak contributions from O $2 p$ states distributed over a wide energy range in the deeper part of the valence band, which caused the shifting of the absorption spectra.

\section{Direct/indirect bandgap nature}

The DOS of $\mathrm{Ta}_{3} \mathrm{~N}_{5}$ was calculated to understand the nature of direct/indirect bandgaps [43, 44, 64]. Our calculated DOS is presented in Fig. 5c, in which the valence band is dominated by completely filled $\mathrm{N} 2 \mathrm{p}$ states and the conduction band is primarily composed of Ta $5 \mathrm{~d}$ states. This compound can be identified as a direct (at the $\Gamma$ or $\mathrm{Y}$ point) or an indirect $(\Gamma-\mathrm{Y})$ semiconductor with the same bandgap energy of $2.2 \mathrm{eV}$. Inconsistent with our work, a previous 
(a)

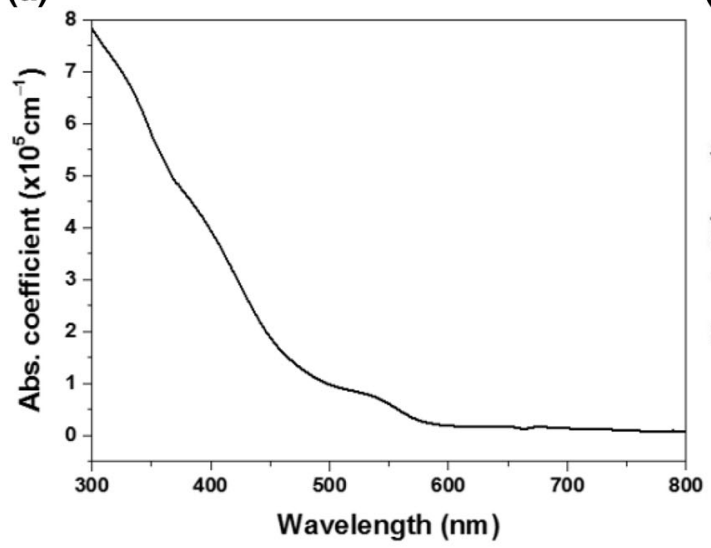

(b)

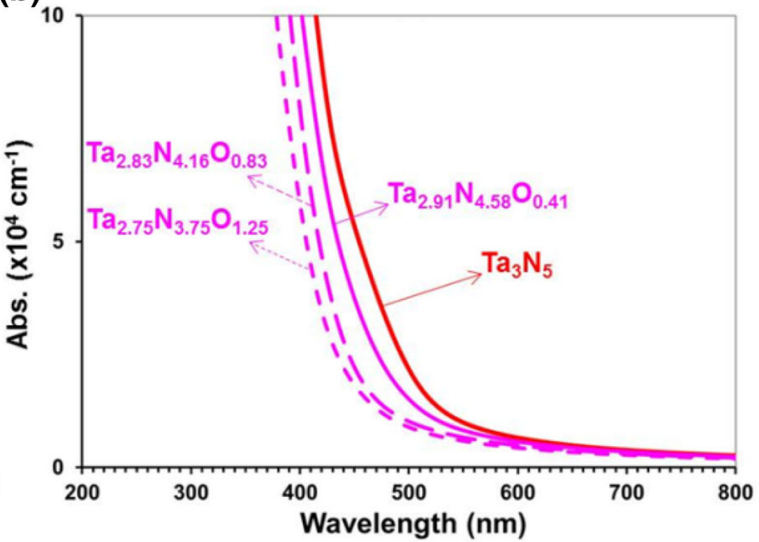

(c)

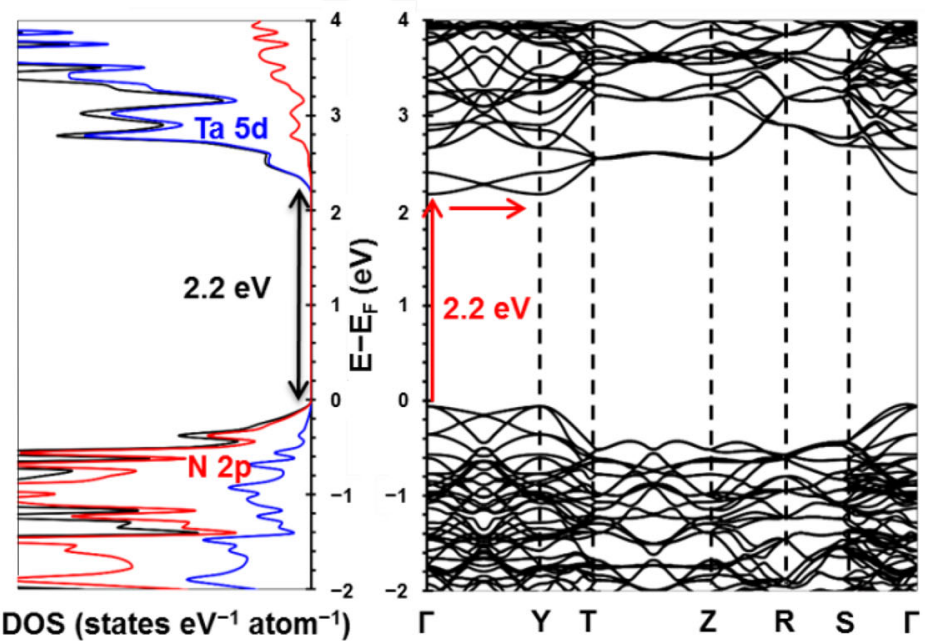

Fig. 5 Absorption coefficient a obtained from experimental measurement, adapted from [41] with permission from the PCCP Owner Societies and $\mathbf{b}$ obtained from theoretical calculation, adapted from [44] with permission from the PCCP Owner Societies, and celectronic density of states (DOS) and $k$-space band structure diagrams

study on calculating the DOS of $\mathrm{Ta}_{3} \mathrm{~N}_{5}$ has shown that it is an indirect bandgap semiconductor with the VBM located at the $\Gamma$ point and the CBM located at the $\mathrm{Y}$ point. The density of states shows that the top of the valence band is primarily composed of $\mathrm{N} 2 \mathrm{p}$ orbitals, whereas the bottom of the conduction band is mainly composed of Ta $5 \mathrm{~d}$ orbitals.

In addition to the DOS calculation and DR-UV-Vis absorption, we studied the photoluminescence (PL) spectra of $\mathrm{Ta}_{3} \mathrm{~N}_{5}$ to investigate its absorption properties [64]. The photoluminescence spectra of $\mathrm{Ta}_{3} \mathrm{~N}_{5}$ were acquired using 473 and $532 \mathrm{~nm}$ lasers as excitation sources. $\mathrm{Ta}_{3} \mathrm{~N}_{5}$ has a quite narrow PL centered at $580 \mathrm{~nm}$ that is considerably more intense when $\lambda_{\text {ex }}=532 \mathrm{~nm}$ is used. This PL is related to the direct bandgap transition at the $\Gamma$ point $(2.2 \mathrm{eV})$ with slightly lower energy for the absorption onset due to non-radiative recombination. computed at the DFT/HSE06 level of theory for $\mathrm{Ta}_{3} \mathrm{~N}_{5}$. Color legend: total DOS (black) and the partial contributions from Ta $5 \mathrm{~d}$ orbitals (blue) and $\mathrm{N} \mathrm{2p}$ orbitals (red). Fermi level is set at $0 \mathrm{eV}$, adapted from [64] by permission of Elsevier

\section{Band position}

The flatband potentials of $\mathrm{Ta}_{3} \mathrm{~N}_{5}$ are typically estimated from Mott-Schottky experiments or ultraviolet photoemission spectroscopy (UPS) measurements [19]. The first study on $\mathrm{Ta}_{3} \mathrm{~N}_{5}$ flatband potentials was reported by Chun et al. utilizing Mott-Schottky and UPS measurements [19]. Both techniques provided good agreement with a flatband potential of $-4.44 \mathrm{eV}(0 \mathrm{~V}$ vs. NHE at $\mathrm{pH}=0)$. Another work by Cong et al. [24] found the flatband potential of $\mathrm{Ta}_{3} \mathrm{~N}_{5}$ to be $-0.05 \mathrm{~V}$ vs. NHE $(\mathrm{pH}=0)$.

In our work, we utilized a Mott-Schottky experiment to estimate the $\mathrm{Ta}_{3} \mathrm{~N}_{5}$ flatband potential [43, 44]. The MottSchottky analysis at $\mathrm{pH} 13.5$ provided a flatband potential of $\sim-0.5 \mathrm{~V}$ vs. RHE. The experimentally obtained flatband potential is considered to be located close to the conduction band and is consistent with the fact that the 
contribution of conduction bands is commonly strongly associated with empty Ta $\mathrm{d}^{0}$ orbitals for $\mathrm{Ta}_{3} \mathrm{~N}_{5}$. Here, the band positions are assumed to follow a typical $\mathrm{pH}$ dependence relationship of $0.059 \times \mathrm{pH}($ in $\mathrm{V})$ such that the band positions relative to water redox potentials remain constant at any $\mathrm{pH}$ [19]. In addition, the slope of the Mott-Schottky graph exhibited a positive value, characteristic of n-type semiconductors. From the bandgap obtained from the measurement of optical properties, the measured conduction and valence band positions are located at $\sim-0.5$ and $1.6 \mathrm{~V}$ vs. SHE (at $\mathrm{pH}$ 0). Based on these data, the band positions for $\mathrm{Ta}_{3} \mathrm{~N}_{5}$ are suitably located for overall water splitting (they straddle the water redox potentials).

The band positions of $\mathrm{Ta}_{3} \mathrm{~N}_{5}$ were predicted through theoretical calculations [44]. For pure $\mathrm{Ta}_{3} \mathrm{~N}_{5}$, the HSE06 calculations predict the $\mathrm{VB}$ edge position to be $0.3 \mathrm{eV}$ higher in energy than the $\mathrm{O}_{2} / \mathrm{H}_{2} \mathrm{O}$ level. The $\mathrm{CB}$ edge position is found to be $1.3 \mathrm{eV}$ higher in energy than the $\mathrm{H}^{+} / \mathrm{H}_{2}$ level. Because of its unsuitable VB edge position with respect to the $\mathrm{O}_{2} / \mathrm{H}_{2} \mathrm{O}$ potential, pure $\mathrm{Ta}_{3} \mathrm{~N}_{5}$ is predicted to be a good candidate only for the hydrogen evolution reaction. It is important to discuss here the potential error bars in the calculation of the band edge positions. General benchmarks are available for the ionization potential and electron affinities of molecular sets, and they indicate a mean absolute error of $\sim 0.2 \mathrm{eV}$. Regardless, the VB edge position is not below the $\mathrm{O}_{2} / \mathrm{H}_{2} \mathrm{O}$ level, and thus, the holes created upon photon absorption in pure $\mathrm{Ta}_{3} \mathrm{~N}_{5}$ will have a very limited (if not null) capability to oxidize water. Additionally, the $\mathrm{pH}$ value is able to slightly affect the $\mathrm{O}_{2} / \mathrm{H}_{2} \mathrm{O}$ potential. In contrast, the position of the $\mathrm{CB}$ band edge is undoubtedly above the $\mathrm{H}^{+}$/ $\mathrm{H}_{2}$ level, and the excited electrons thus have a strong capability to reduce $\mathrm{H}^{+}$.

The predicted band edge positions for pure $\mathrm{Ta}_{3} \mathrm{~N}_{5}$ are found to differ from the experimental results. For the experimental results, the measurements and calculations are based on the Mott-Schottky relationship, where the surface states may present and play a crucial rule in modifying the band positions [19, 24, 43, 44]. This effect, however, was not taken into account for the theoretical calculations. In addition, as mentioned previously, the formation of pure $\mathrm{Ta}_{3} \mathrm{~N}_{5}$ is not possible. Although the XRD patterns show the pure phase, the elemental analysis shows a considerable amount of remaining oxygen for $\mathrm{Ta}_{3} \mathrm{~N}_{5}$, which indicates an oxygen-enriched $\mathrm{Ta}_{3} \mathrm{~N}_{5}$ crystal structure. Our group has systematically predicted the band edge positions of various oxygen-rich $\mathrm{Ta}_{3} \mathrm{~N}_{5}$ structures through theoretical calculations. The measured band edge positions are found to be highly consistent with the band edge positions for O-enriched $\mathrm{Ta}_{3} \mathrm{~N}_{5}$ materials, particularly for the non-stoichiometric $\left.\left.\mathrm{Ta}_{3-\mathrm{x}}\right) \mathrm{N}_{(5-5 \mathrm{x}}\right) \mathrm{O}_{5 \mathrm{x}}$ (for $x \geq 0.16$ ) compounds. Considering the accuracy of bandgap prediction using the HSE06 functional, this result confirms that the experimentally prepared tantalum nitride materials are not stoichiometric but rather strongly enriched in $\mathrm{O}$, as also observed from Raman and DR-UV-Vis absorption spectra.

The optical properties and band positions based on our experimental results and calculations and those reported in the literature are compared in Table 2.

\section{Kinetic and dynamic properties of photoexcited carriers on $\operatorname{Ta}_{3} N_{5}$}

\section{Charge carrier separation}

In photocatalytic reactions, it is important to examine the separation of charge carriers in the photocatalyst. The dielectric constant is an important parameter that describes the interaction of the electric field with the material's medium. As defined by many researchers $[66,67,76,79-83,84]$, the extraction of charge is greatly dependent on the material's dielectric constant. In general, a high dielectric constant (10 or more) was found to induce good exciton dissociation into free charge carriers. Furthermore, knowing the dielectric constant allows the donor density of the material to be calculated, which is an important parameter for describing the intrinsic nature of semiconductors. In general, the dielectric constant is dependent on the different vibrational modes induced by time scale variations. At low frequency, there is only an ionic contribution called the vibrational dielectric constant $\left(\varepsilon_{\mathrm{vib}}\right)$. At high frequency, there is an additional contribution coming from the electronic vibrational mode $\left(\varepsilon_{\infty}\right)$. For $\mathrm{Ta}_{3} \mathrm{~N}_{5}, \varepsilon_{\text {vib }}$ is almost used as 110 [21]. We calculated the imaginary part of the frequencydependent dielectric function over the three principal light polarization vectors as a function of the photon energy using the DFPT/HSE06 method, and the obtained spectra are displayed in Fig. 6a [64]. High dielectric constants of 35.15, 39.68 , and 53.88 were obtained along the principal crystallographic directions with an average value of 43 . For the electronic dielectric constant contribution, it was calculated using density functional perturbation theory at the DFT/PBE level of theory and at the experimental geometry, as well as by employing the QE code. It was found to be between 8 and $11.5[67,70,77]$.

In our previous work, we reported the measurement of the dielectric constant of $\mathrm{Ta}_{3} \mathrm{~N}_{5}$ films from the fringes observed in the transmittance and/or reflectance spectra [41]. The details of the measurements and calculations were also described. The dielectric constants for different film thicknesses are presented in Table 3. Experimentally, to estimate the electronic vibration of the dielectric constant, we use the complex index of refraction $N=n+i k$. From the fringes observed in the transmittance and/or reflectance spectra, we can deduce the dielectric constant 
Table $2 \mathrm{Ta}_{3} \mathrm{~N}_{5}$ optical properties and band positions

\begin{tabular}{|c|c|c|c|}
\hline Optical properties & Calculation & Experimental & Method/references \\
\hline \multicolumn{4}{|c|}{ Bandgap energy (eV) } \\
\hline & & 2.1 & DR-UV-Vis [19-21, 40-48] \\
\hline & & 2.1 & UV-Vis $[41,100]$ \\
\hline & $2.20^{\mathrm{D}}$ & & DFT-HSE06 [44, 64] \\
\hline & $2.20^{\mathrm{I}}$ & & DFT-HSE06 [64] \\
\hline & $1.43^{\mathrm{I}}$ & & PBE [67] \\
\hline & $1.88^{\mathrm{I}}$ & & PBE [67] \\
\hline & $2.12^{\mathrm{D}}$ & & Sc-hybrid [67] \\
\hline & $2.90^{\mathrm{I}}$ & & PBE0 [70] \\
\hline & $2.20^{\mathrm{I}}$ & & HSE [69] \\
\hline \multicolumn{4}{|c|}{ Flatband potential (V vs. NHE) } \\
\hline & & $0(\mathrm{pH} 0)$ & Mott-Schottky [19] \\
\hline & & -0.02 & UPS [19] \\
\hline & & $-0.05(\mathrm{pH} 0)$ & Mott-Schottky [24] \\
\hline & & $-0.3(\mathrm{pH} 13)$ & Mott Schottky $[41,43,44]$ \\
\hline \multicolumn{4}{|l|}{ Conduction band } \\
\hline & & $-0.3(\mathrm{pH} 0)$ & Mott-Schottky [19] \\
\hline & & $-0.52(\mathrm{pH} 0)$ & UPS [19] \\
\hline & $-1.3(\mathrm{pH} 0)$ & & HSE06 [74] \\
\hline & $-0.4\left(\mathrm{pH} 0\right.$, defective $\left.\mathrm{Ta}_{3} \mathrm{~N}_{5}\right)$ & & HSE06 [74] \\
\hline \multicolumn{4}{|l|}{ Valence band } \\
\hline & & $+1.58(\mathrm{pH} 0)$ & Mott-Schottky [19] \\
\hline & & $+1.58(\mathrm{pH} 0)$ & UPS [19] \\
\hline & $+0.9(\mathrm{pH} 0)$ & & HSE06 [74] \\
\hline & $+1.6\left(\mathrm{pH} 0\right.$, defective $\left.\mathrm{Ta}_{3} \mathrm{~N}_{5}\right)$ & & HSE06 [74] \\
\hline \multicolumn{4}{|c|}{ Absorption coefficient $\left(\mathrm{cm}^{-1}\right)$} \\
\hline & $1 \times 10^{5}$ & & HSE06 $[44,64]$ \\
\hline & & $8 \times 10^{5}-1 \times 10^{4}$ & UV-Vis spectroscopy [41] \\
\hline & & $6.2 \times 10^{4}$ & UV-Vis spectroscopy [60] \\
\hline & & $2.5 \times 10^{5}-3 \times 10^{3}$ & Spectroscopic ellipsometry [75] \\
\hline & $1.4 \times 10^{5}-2.2 \times 10^{5}$ & & BSE- $\mathrm{G}_{0} \mathrm{~W}_{0}[67]$ \\
\hline
\end{tabular}

$D$ direct bandgap, $I$ indirect bandgap

$\varepsilon_{1}=n^{2}-k^{2} \approx n^{2}$ (for low absorption) and $\varepsilon_{2}=2 n k$. Thus, the obtained dielectric constants were approximately 12.5 and 13 in the visible spectral range for $\mathrm{Ta}_{3} \mathrm{~N}_{5}-160 \mathrm{~nm}$ and $\mathrm{Ta}_{3} \mathrm{~N}_{5}-470 \mathrm{~nm}$, respectively [26, 41]. Because of the very thin thickness of the $\mathrm{Ta}_{3} \mathrm{~N}_{5}-50 \mathrm{~nm}$ sample, there were no fringes observed. Therefore, we can use another formalism to extract dielectric constant. We calculated the dielectric constant from a calculation of the real part of the index of refraction from the reflectance and transmittance measurements [78]. The real part of the dielectric constant is linearly related to the wavelength in the non-absorbing region [78]. Figure $6 \mathrm{~b}$ shows the plot of $\varepsilon_{1}$ vs. $\lambda^{2}$ for the $\mathrm{Ta}_{3} \mathrm{~N}_{5}-50 \mathrm{~nm}$ thin films. The intersection of the linear part of this curve provides the value of the dielectric constant, and the $\mathrm{N} / \mathrm{m}^{*}$ ratio can be calculated from the slope of the straight line. From this extrapolation, we determined the dielectric constant to be equal to 13.8. Moreover, we can estimate the relative mass of the material. Indeed, relative mass is another important parameter that can provide an idea about the charge diffusion in the photocatalyst. It will be developed in the following section.

Clearly, there is a significant difference among the measured and theoretically calculated dielectric constants $[41,64]$. For the measured dielectric constant, the experiment was conducted only for high frequency (UV-Vis range), where it contributes only to electronic vibration, whereas for the calculated dielectric constant, both low and high frequencies were taken into account, and therefore, the dielectric constant also considered the ionic and electronic contributions [41, 64, 66]. 


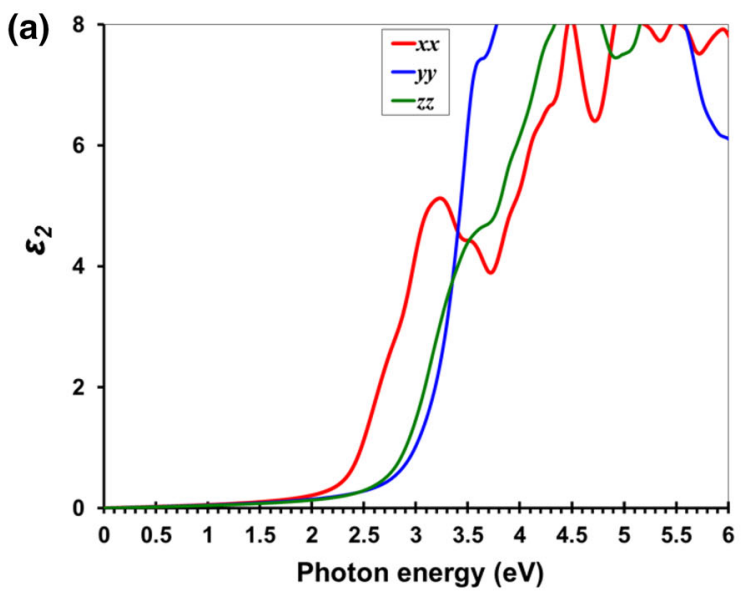

Fig. 6 a Imaginary part of the frequency-dependent dielectric function along with the three principal light polarization vectors computed at the DFPT/HSE06 level of theory for $\mathrm{Ta}_{3} \mathrm{~N}_{5}$ utilized for dielectric constant calculation. Red, blue, and green curves

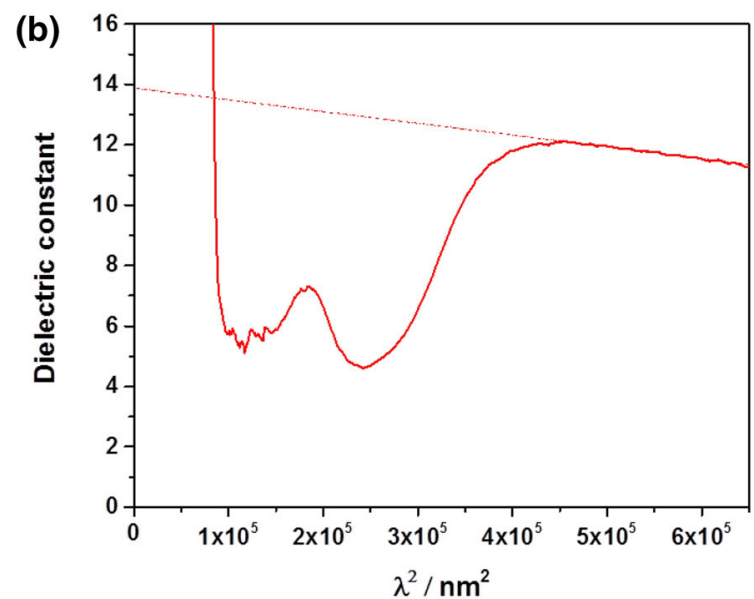

correspond to $x x, y y$, and $z z$ components, respectively, adapted from [64] by permission of Elsevier and $\mathbf{b}$ plot of the dielectric constant vs. $\lambda^{2}$ of $\mathrm{Ta}_{3} \mathrm{~N}_{5}$ thin film for electron effective mass determination

Table $3 \mathrm{Ta}_{3} \mathrm{~N}_{5}$ kinetic and dynamic properties

\section{Kinetic and dynamic properties}

Dielectric constant ${ }^{\mathrm{a}}$

Electron Effective mass ${ }^{\mathrm{c}}$

Hole Effective mass ${ }^{c}$

43

110

$7-9$

65

$$
\begin{aligned}
& 0.60 m_{0}-1.94 m_{0} \\
& 0.23 m_{0}-2.70 m_{0}
\end{aligned}
$$

$$
0.36 m_{0}
$$

$$
\begin{aligned}
& 0.85 m_{0}-3.38 m_{0} \\
& 0.66 m_{0}-3.56 m_{0}
\end{aligned}
$$

Charge carrier concentration $\left(\mathrm{cm}^{-3}\right)$

Mobility $\left(\mathrm{cm}^{2} \mathrm{~V}^{-1} \mathrm{~s}^{-1}\right)$

Carrier lifetime (ps)$$
1.3-4.4
$$

Diffusion length (nm)

$$
\text { 3-9 }
$$

Method/references

LR-DFPT-PBE [64]

Reflectance fringe [41]

Not specified [21]

Spectroscopic ellipsometry [75]

PBE [67]

FD-DFT-HSE06 [64]

DFT-PBE [67]

Reflectance measurement [40, 41]

FD-DFT-HSE06 [64]

DFT-PBE [67]

Hall effect measurement [41]

Mott-Schottky plot [21]

Van der Pauw [41]

Transient spectroscopy [41]

Femtosecond DR-spectroscopy [86]

Subtracted from mobility and lifetime [41]

$A$ average value for different crystal orientations, calculated as the total dielectric constant considering ionic and electronic contributions (i.e., low and high frequencies), $b$ measured only for high frequency (electronic contribution), $c$ depending on crystal orientation

\section{Charge carrier diffusion}

Quantitatively, charge carrier diffusion can be examined from the effective mass property. Acceptable effective masses are considered optimal, at least in one crystallographic direction, when they are less than $0.5 m_{0}\left(m_{0}\right.$ being the electron mass) for an efficient diffusion of charge carriers in the material [64, 66, 79-83]. For a measured 
donor density of $5 \times 10^{20} \mathrm{~cm}^{-3}$, deduced from MottSchottky measurements, we estimate the electron effective mass to be $0.36 m_{\mathrm{e}}^{*}$ for $\mathrm{Ta}_{3} \mathrm{~N}_{5}-50 \mathrm{~nm}$ using Fig. 6b. We also computed the charge carrier effective masses (i.e., electron and hole effective masses) and compared them to previous experimental works on semiconductors used in photovoltaic devices. The smallest hole and electron effective masses are both found to be along either the [001] or [010] direction with $m_{\mathrm{h}}^{*}=0.85 m_{0}$ and $m_{\mathrm{e}}^{*}=0.6 m_{0}$, and the highest hole and electron mobilities are expected to be along these two specific directions. These two obtained values are larger than $0.5 m_{0}$ (threshold value), and hence, relatively poor charge carrier transport properties are expected along this specific direction. Note that the current data using the DFT/HSE06 level of theory had a subtle discrepancy with the reported values using the DFT/PBE level of theory [85], as expected from the different calculated energy diagrams. In addition, compared to the calculated electron effective mass obtained from measurements, $0.36 m_{0}$, the value is below the threshold, and thus, good electron charge carrier transport is expected. Calculations estimate the electron effective masses to be between $\left(0.2-2.7 m_{\mathrm{e}}^{*}\right)$ [64, 67] depending on the crystallographic direction. Additionally, it appears that the effective masses of holes are larger than those for electrons $\left(0.66-3.6 m_{\mathrm{h}}^{*}\right)$. This result suggests that low hole mobility may be responsible for the limitation of the generated photocurrent in $\mathrm{Ta}_{3} \mathrm{~N}_{5}$.

The charge carrier concentration can be calculated from the slopes of the Mott-Schottky plots. Using a geometric area of the films, the obtained values were $\sim 5 \times 10^{19} \mathrm{~cm}^{-3}$ for the thin films and $5 \times 10^{20} \mathrm{~cm}^{-3}$ for the thicker ones. If the relative surface area of the thicker film was used, the carrier concentration of this film was in the same range as the rest of the samples. Clearly, the donor density measurement from the Mott-Schottky analysis is very complex; therefore, the carrier concentrations of the films were also measured using Hall measurements. We found values between $5 \times 10^{17}$ and $5 \times 10^{20} \mathrm{~cm}^{-3}$, which are within the same range for other reported photoanodes, such as hematite or bismuth vanadate materials [103-105]. We also reported on the electronic transport properties (carrier mobility) and spectroscopic measurements (carrier recombination). These two parameters determine the diffusion length of the material and can be correlated to the PEC performances. The van der Pauw four-probe measurement provides the resistivity of the material, and the Hall measurements provide the charge carrier concentration. The resistivity of the films decreased from 32.44 to $0.01 \mathrm{O} \mathrm{cm}$ with a thickness increase from 160 to $470 \mathrm{~nm}$, which correlates to the crystallinity of the films. For the thick films $(960 \mathrm{~nm})$, the resistivity increased to $54.88 \mathrm{O} \mathrm{cm}$. All of these values are within the range of typical semiconductor materials $\left(10^{-3}-10^{3} \Omega \mathrm{cm}\right)$. The calculated mobilities were in the range of $1.3-4.4 \mathrm{~cm}^{2}$ $\mathrm{V}^{-1} \mathrm{~s}^{-1}$. Thicker films possess better mobility.

The intrinsic defects in $\mathrm{Ta}_{3} \mathrm{~N}_{5}$ can significantly reduce the carrier lifetime and consequently decrease the photocurrent. It is well known that the carrier lifetime is significantly increased by enhancing the film morphology, grain size, and crystallinity. Femtosecond (fs) transient absorption spectroscopy provides direct information regarding the carrier dynamics and excited-state deactivation pathways, including carrier trapping. We utilized this method to probe the events that occurred due to photoexcitation of the $\mathrm{Ta}_{3} \mathrm{~N}_{5}$ films. We explored the carrier dynamics of $\mathrm{Ta}_{3} \mathrm{~N}_{5}$ thin films using broadband transient absorption spectroscopy with $120 \mathrm{fs}$ temporal resolution. We observed a significant increase in the carrier lifetime of the thick films compared with the thinner films. The observed dynamics can be attributed to the decrease in carrier trapping, indicating that there are less defects in the thicker film compared with the thinner one, consistent with the crystalline structure and the surface morphology of the thick films. The measured lifetimes are in the range of 3.1-8.7 ps, consistent with the $12 \mathrm{ps}$ reported for $\mathrm{Ta}_{3} \mathrm{~N}_{5}$ powder [86]. Using the mobility and lifetime, we can estimate the $\mathrm{Ta}_{3} \mathrm{~N}_{5}$ diffusion length to be between 3 and $9 \mathrm{~nm}$, which again highlights the difficulty in diffusing charge carriers. Material structuration and cocatalyst addition are mandatory to diffuse charge carriers and subsequently improve the photocatalytic reaction.

The kinetic and dynamic properties from our experimental and theoretical calculation results and those reported in the literature are compared in Table 3.

\section{$\mathrm{Ta}_{3} \mathbf{N}_{5}$-electrolyte interface}

\section{Surface states related phenomena}

The photocatalytic activity of $\mathrm{Ta}_{3} \mathrm{~N}_{5}$ for oxygen and hydrogen evolution reactions has primarily been attributed to its activity related to its bulk properties, such as crystallinity, particle size, and optical properties [18-20, 22, 23, $26,29,30]$. However, as previously described, photocatalytic water splitting is a complex reaction that is affected by many factors associated with the photocatalyst and cocatalyst properties. Although the effect of the surface properties of semiconductors is significant, it is less investigated and correlated with photocatalytic activity.

Our work reported that not only the bulk properties but also the surface properties greatly affected the photocatalytic activity of $\mathrm{Ta}_{3} \mathrm{~N}_{5}$ [43]. A thin TaN layer on the surface $(\sim 2 \mathrm{~nm})$, which formed depending on the synthesis method, was observed to change the energetic profile 
on the $\mathrm{Ta}_{3} \mathrm{~N}_{5}$-electrolyte interface, thus changing the photocatalytic activity. The surface layer changes the potential distribution on the $\mathrm{Ta}_{3} \mathrm{~N}_{5}$ surface-electrolyte interface, as evidenced by the perturbed flatband potential. The flatband potentials shifted as a consequence of Fermi level pinning of the semiconductor-electrolyte interface due to the drastic influence of surface states. However, the surface states were difficult to elucidate in this study, but it can be said that the layer, which can be removed by alkaline piranha solution, shifted the overall flatband potential to be more negative without changing the bandgap, consistent with the enhanced hydrogen evolution while minimizing the oxygen evolution. This study also emphasized the importance of surface modification to improve the photocatalytic performance. Interface modification together with cocatalyst function and intentional perturbation of the surface states by introducing an additional hetero-layer would have the potential to further improve the photocatalytic performance.

\section{Mott-Schottky analysis}

One of the requirements of a photocatalyst to undergo photocatalytic/PEC reactions is possessing suitable band positions with respect to the water redox potentials (thermodynamic requirement). To estimate the band positions, Mott-Schottky plots using impedance spectroscopy were obtained in an attempt to retrieve the flatband potential [26, 41]. Note that the Mott-Schottky relation is only applicable to "ideal" semiconductors with a uniform bulk and surface and with preferably known surface areas. Additionally, the surface states present on the semiconductor significantly affect the Mott-Schottky plot because the $\mathrm{pH}$ effects follow the Nernstian relationship of $-59 \mathrm{mV} \mathrm{pH}^{-1}$ for many semiconductors. Hence, the fabrication of high-quality electrodes using powder semiconductors is indispensable for obtaining reliable results $[26,41]$.

Several works have reported the flatband potentials of $\mathrm{Ta}_{3} \mathrm{~N}_{5}$ films synthesized using different methods, where the reported flatband potentials show different values for different film preparations [19, 24, 41]. In addition to films synthesized from $\mathrm{Ta}_{3} \mathrm{~N}_{5}$ by applying electrophoretic deposition, we applied the sputtering method to synthesize $\mathrm{Ta}_{3} \mathrm{~N}_{5}$ on Ta foils with different thicknesses [41, 43, 44]. The Mott-Schottky plots for the $\mathrm{Ta}_{3} \mathrm{~N}_{5}$ films with different thicknesses were determined based on the impedance data. All of the $\mathrm{Ta}_{3} \mathrm{~N}_{5}$ films exhibited positive slopes, which are characteristic of n-type semiconductors.

To obtain accurate flatband potentials, the selection of a suitable potential window for extrapolation from the MottSchottky plots is crucial. For this purpose, the Faradaic current should remain negligible. However, in most cases, the non-flat behavior of the capacitive current causes difficulty in selecting the right potential window for measuring the flatband potential. For example, in our case, in the potential range from -1.2 to $+1.0 \mathrm{~V}$ vs. RHE, the MottSchottky analysis leads to a flatband potential from -0.1 to $0 \mathrm{~V}$ vs. RHE, which is consistent with previously reported values. However, in a different potential range at more positive potentials, the flatband potential can be found between +0.8 and $+1.1 \mathrm{~V}$ vs. RHE, which are more positive compared with those reported. Notably, the flatband potentials mentioned in the literature were taken in different potential ranges, resulting in different flatband potentials. Mott-Schottky analysis is more preferable for studying the flatband potential of a single-crystal semiconductor with a moderate doping content and a good ohmic contact [26, 41,87]. These ideal conditions are not the case for these samples nor those reported in the literature. Additionally, due to the surface state capacitance and associated double-layer capacitance at the semiconductorelectrolyte interface, it is often observed that the flatband potential depends on the frequency used, which should not be the case.

Upon successful charge transfer, the culmination of all the photophysical processes on the semiconductor surface succeeds with an effective electrocatalytic process $[1,26,88]$. An efficient electrocatalyst is one of the most important parameters for achieving efficient photocatalytic water splitting in visible light. To achieve efficient water splitting under visible light irradiation where there is no significant overpotential for electrocatalysis, the electrocatalysts need to transfer the received electrons and holes to the relevant reactants in the water splitting redox reactions $[1,26]$.

\section{OER cocatalyst deposition effect on $\mathrm{Ta}_{3} \mathrm{~N}_{5}$}

A comprehensive understanding of the cocatalyst and of its fundamental effect on photocatalytic water splitting has yet to be elucidated. Studies on electrochemical water splitting have obtained some promising results regarding the development of oxygen evolution reaction (OER) cocatalysts. Some new cocatalysts, such as $\mathrm{Co}_{3} \mathrm{O}_{4}, \mathrm{Ni}(\mathrm{OH})_{2}$, and $\mathrm{Mn}_{3} \mathrm{O}_{4}$, have good potential for replacing the employed noble metal catalysts $\left(\mathrm{RuO}_{2}\right)$ because of their excellent electrocatalytic activity [76, 87-90]. However, little attention has been focused on investigating these materials as OER cocatalysts in photocatalytic water splitting. Despite the difference in these two systems, this electrochemical approach is applicable for studying the surface reaction of water oxidation. 


\section{Physical and chemical properties of $\mathrm{CoO}_{x}$ on $\mathrm{Ta}_{3} \mathrm{~N}_{5}$ surface}

Cobalt oxide $\left(\mathrm{CoO}_{\mathrm{x}}\right)$ has been extensively investigated as a cocatalyst, particularly for electrochemical and PEC OER [15, 24, 91-98]. Although many studies have reported improvement of the electrochemical OER using $\mathrm{CoO}_{\mathrm{x}}$, studies on powder suspension systems are limited [42, 93]. An improved photocatalytic OER rate with a quantum efficiency as high as $27 \%$ (at $440 \mathrm{~nm}$ ) has been reported on $\mathrm{LaTiO}_{2} \mathrm{~N}$ with deposited $\mathrm{CoO}_{\mathrm{x}}$ [93]. In addition to providing active sites for the electrocatalytic $\mathrm{OER}, \mathrm{CoO}_{\mathrm{x}}$ is also believed to play a vital role in promoting charge separation. However, despite the tremendous efforts toward developing a $\mathrm{CoO}_{\mathrm{x}}$ catalyst, its chemical state and properties on a photocatalyst have yet to be elucidated.

In our recent work, quantum efficiencies as high as $19.4 \%$ (at $440 \mathrm{~nm}$ ) were achieved on $\mathrm{CoOx} / \mathrm{Ta}_{3} \mathrm{~N}_{5}$ in the presence of $\mathrm{AgNO}_{3}$ as a sacrificial electron acceptor [99]. The effect of $\mathrm{CoO}_{\mathrm{x}}$ addition and heat treatment on the photocatalytic OER on $\mathrm{Ta}_{3} \mathrm{~N}_{5}$ was investigated based on the photocatalytic OER performance and thorough characterization. Nitridation after Co impregnation essentially creates a metallic cobalt-cobalt oxide core shell structure with intimate contact between the $\mathrm{Ta}_{3} \mathrm{~N}_{5}$ surface and the cocatalyst, as indicated by STEM image depicted in Fig. 7a, b.

This intimate contact led to drastic improvements in the photocatalytic efficiency for the OER. This state is also consistent with the results obtained by Raman, XAS, and XPS measurements. However, the metallic state of cobalt is not an essential component of the improved OER because it disappeared after the photocatalytic reaction. The high-temperature treatment is likely to form an intimate contact between the $\mathrm{Ta}_{3} \mathrm{~N}_{5}$ surface and $\mathrm{CoO}_{\mathrm{x}}$, facilitating effective hole transfer. Subsequent mild oxidation led to further improvement of the photocatalytic OER, indicating that $\mathrm{CoO}_{\mathrm{x}}$ is a preferred active site for the OER over the metallic phase. The photocatalytic OER activity using $\mathrm{Ta}_{3} \mathrm{~N}_{5}$ as photocatalyst from our study and that reported in literature are compared in Fig. 8a, b.

\section{Kinetics and dynamics of photoexcited carriers on $\mathrm{CoO}_{\mathrm{x}} / \mathrm{Ta}_{3} \mathrm{~N}_{5}$ and noble metal co-loaded $\mathrm{CoO}_{\mathrm{x}} /$ $\mathbf{T a}_{3} \mathbf{N}_{5}$}

The effect of cocatalyst modification on improved photocatalytic/PEC performance has been a matter of debate. The role of the cocatalyst has been reported to provide two effects: 1) improvement in electrochemical performance by lowering the overpotentials for the redox reactions, and 2) effectively separating the excited charges utilizing the photocatalyst (semiconductor)-catalyst interface through the differences in Fermi levels between them.
In a previous work, a substantial improvement of the electrocatalytic OER was observed when Au was added to the $\mathrm{CoO}_{\mathrm{x}}$ electrode [91]. The beneficial effects of the two coexisting metals were speculated to be increasing the population of $\mathrm{Co}^{\mathrm{IV}}$, which are believed to be the active sites for the OER. Knowing that $\mathrm{CoO}_{\mathrm{x}}$ is a more preferable active site for the photocatalytic OER, we attempted to improve the OER rate by simply adding a trace amount ( $\sim 0.05 \mathrm{wt} \%)$ of noble metals to a cobalt-modified $\mathrm{Ta}_{3} \mathrm{~N}_{5}$. The photocatalytic OER over Pt or Ir co-loaded $\mathrm{CoO}_{\mathrm{x}} /$ $\mathrm{Ta}_{3} \mathrm{~N}_{5}$ is presented in Fig. 9.

The optimized system exhibited one of the highest quantum efficiencies (QEs) reported over $20 \%$ in visible light range in $0.1 \mathrm{M} \mathrm{Na}_{2} \mathrm{~S}_{2} \mathrm{O}_{8}$ at $\mathrm{pH} 14$. Using time-resolved spectroscopy, we are attempting to identify whether hole transfer kinetics is improved by the addition of noble metal. The initial attempts likely suggest that hole transfer was also improved, and the results are to be published in the near future. In addition, as claimed in the literature, improved electrocatalytic OER by lowering the onset potential also plays a significant role in enhancing the photocatalytic OER [90].

As previously mentioned, investigating electrocatalysis is one of the best approaches for studying photocatalytic water splitting. In our recent review, we included the mass transfer of reactants, which significantly affects the photocatalytic water splitting performance [26]. The study of photocatalytic water splitting has primarily focused on developing efficient materials, including cocatalysts, without consideration of thermodynamic and kinetic information from the electrocatalysis perspective. Indeed, in a single powder photocatalyst system, there is no $\mathrm{pH}$ gradient because the $\mathrm{H}_{2}$ and $\mathrm{O}_{2}$ are generated in the same compartment.

Most of the photocatalytic water splitting is conducted at neutral $\mathrm{pH}$ due to the stability issue of most semiconductor photocatalysts. Therefore, it is important to study the electrolysis of water under neutral $\mathrm{pH}$. In acidic or alkaline conditions, $\mathrm{pH} 0$ and 14 , respectively, one $\mathrm{H}^{+}$or $\mathrm{OH}^{-}$ion is present among approximately $55 \mathrm{H}_{2} \mathrm{O}$ molecules. In terms of kinetics, the reaction with hydronium ions (protons) or hydroxyl ions that have a very large diffusion coefficient is more facile than that with water molecules for reduction and oxidation, respectively $[26,100]$. In neutral conditions, however, a different reaction mechanism has been observed [26, 101]. Insufficient hydronium/hydroxyl ion activities at near-neutral $\mathrm{pH}$ induced the limiting diffusion currents of reactions with these ions. In this condition, buffering actions are effective based on the reactant switching over varied $\mathrm{pH}$ [101]. In addition, for electrochemical measurements, the supporting electrolyte is an essential component for avoiding solution resistance ( $\mathrm{R}$ drop). We recently reported a rigorous study on the effect of a supporting electrolyte for electrochemical hydrogen

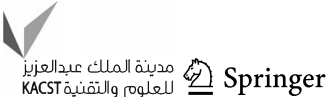


(a)

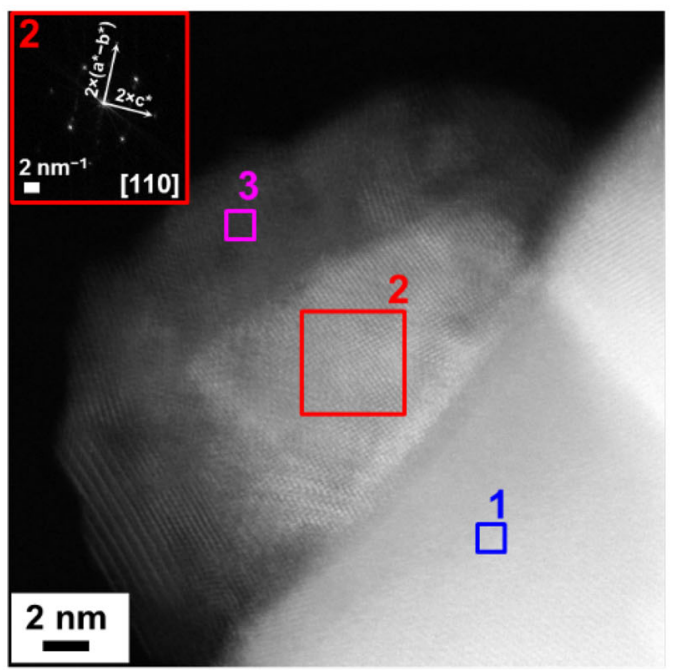

Fig. 7 a Dark field HR-STEM for core-shell agglomerated cobalt nanoparticles. The inset shows the FFT results of the core region and depicts a characteristic fcc pattern viewed along the [110] zone axis,

(a)

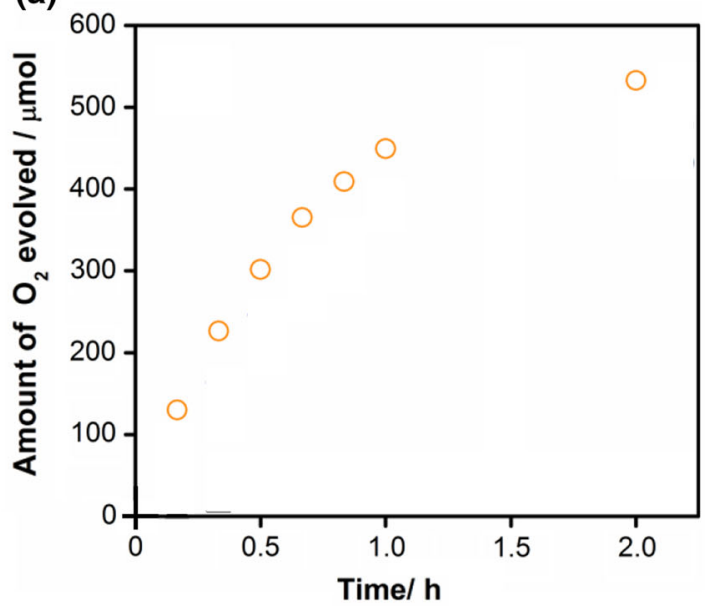

Fig. 8 Time course of photocatalytic OER on a 2 wt $\% \mathrm{CoO}_{\mathrm{x}} /$ $\mathrm{Na}_{2} \mathrm{CO}_{3}-\mathrm{Ta}_{3} \mathrm{~N}_{5}$ nitrided at $500{ }^{\circ} \mathrm{C}$ for $1 \mathrm{~h}$, adapted with permission from [42] Copyright (2012) American Chemical Society, and b on nitrided $2 \mathrm{wt} \% \mathrm{CoO}_{\mathrm{x}} / \mathrm{Ta}_{3} \mathrm{~N}_{5}$ with and without oxidation at $200{ }^{\circ} \mathrm{C}$ for

evolution under neutral conditions in a buffered system [102]. However, there is a lack of information available regarding this $\mathrm{pH}$ and the electrolyte effect in photocatalytic water splitting.

We attempted to study the photocatalytic OER using $\mathrm{CoO}_{\mathrm{x}} / \mathrm{Ta}_{3} \mathrm{~N}_{5}$ at different $\mathrm{pH}$ (alkaline conditions) in the presence of $0.1 \mathrm{M} \mathrm{Na} \mathrm{Na}_{2} \mathrm{O}_{8}$ as a sacrificial electron acceptor. Alkaline conditions were selected due to the stability of $\mathrm{CoO}_{x}$ species, which is not stable under neutral or acidic conditions. Hence, selecting a cocatalyst that is (b)

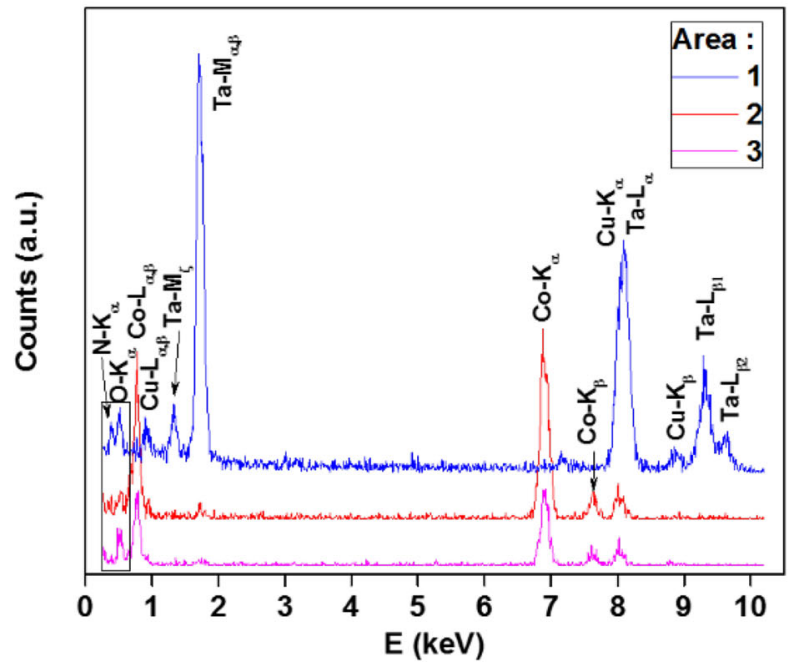

b X-ray fluorescence spectra of $\mathrm{Ta}_{3} \mathrm{~N}_{5}(1)$, the core (2) and the shell (3) of an agglomerate as depicted on (a). Figures adapted with permission from [99] Copyright (2015) American Chemical Society

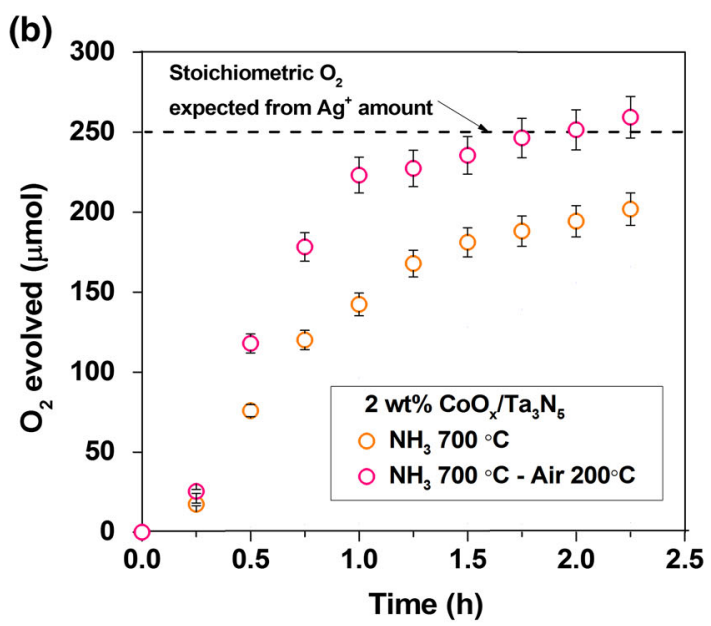

$1 \mathrm{~h}$, adapted with permission from [99] Copyright (2015) American Chemical Society (a 50 and b $10 \mathrm{mM} \mathrm{AgNO}$, at pH $8.5\left(\mathrm{La}_{2} \mathrm{O}_{3}\right.$ buffer) under visible light irradiation $(420<\lambda<800 \mathrm{~nm}))$

stable under a wide range of $\mathrm{pH}$ is essential. As shown in Fig. 10, the photocatalytic OER rate increases with increasing $\mathrm{pH}$. The OER rate increases from 40 to $60 \mu \mathrm{mol} \mathrm{h}{ }^{-1}$ for $\mathrm{pH} 10.5$ to $\mathrm{pH} \mathrm{12,} \mathrm{respectively,} \mathrm{and}$ reaches optimum conditions for $\mathrm{pH} 14$ with an OER rate of $100 \mu \mathrm{mol} \mathrm{h}^{-1}$. This positive trend is associated with improved OER kinetics and a reduced iR drop (solution resistance) for higher $\mathrm{pH}$. A complete study from electrocatalysis and photocatalysis perspectives for different conditions using different catalysts is under development. 


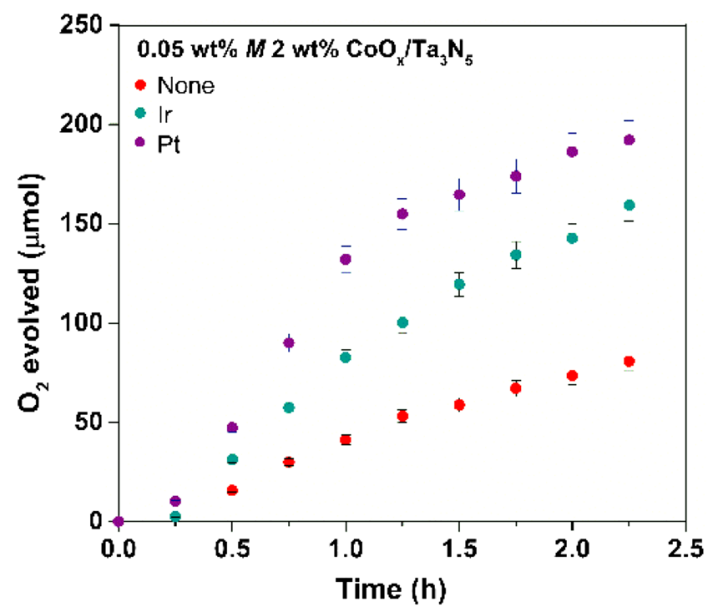

Fig. 9 Time course of photocatalytic OER on $\mathrm{CoO}_{\mathrm{x}} / \mathrm{Ta}_{3} \mathrm{~N}_{5}(0.1 \mathrm{M}$ $\mathrm{Na}_{2} \mathrm{~S}_{2} \mathrm{O}_{8}, \mathrm{pH} 10.5$ adjusted with $\mathrm{NaOH}$ under visible light irradiation $(420<\lambda<800 \mathrm{~nm}))$

\section{Kinetics and activation energy measurement for photocatalytic OER using $\mathrm{NiFeO}_{x}$ catalyst}

Photocatalytic reaction is essentially electrochemical redox reactions driven by photogenerated electrons and holes in the semiconductor. Our attempt is to study electrochemical reaction apart from semiconductor, and then connect to photophysical process using the semiconductor. For this, we used the $\mathrm{NiFeO}_{\mathrm{x}}$ electrocatalyst in alkaline solution as highly active, industrially-vial catalyst [106]. As expected, the catalyst achieved $10 \mathrm{~mA} \mathrm{~cm}{ }^{-2}$ at an overpotential of $260 \mathrm{mV}$ in $1 \mathrm{M}$ of $\mathrm{KOH}$ solution and the different temperature measurement resulted in an apparent activation energy of $25 \mathrm{~kJ} \mathrm{~mol}^{-1}$. The same catalyst was used to decorate $\mathrm{Ta}_{3} \mathrm{~N}_{5}$ powder photocatalyst by applying identical hydrothermal treatment in the presence of $\mathrm{Ta}_{3} \mathrm{~N}_{5}$ powder. The $\mathrm{NiFeO}_{\mathrm{x}} / \mathrm{Ta}_{3} \mathrm{~N}_{5}$ was used for photocatalytic OER reaction in the presence of $0.1 \mathrm{M} \mathrm{Na}_{2} \mathrm{~S}_{2} \mathrm{O}_{8}$ as a strong electron scavenger, thus likely leading to the OER being kinetically relevant. The incorporation of $\mathrm{NiFeO}_{\mathrm{x}}$ catalyst leads to fivefold improvement of $\mathrm{Ta}_{3} \mathrm{~N}_{5}$ photocatalytic OER in the visible range with quantum efficiency up to $24 \%$ at $480 \mathrm{~nm}$. The apparent activation energy for photocatalytic OER was found to be $16 \mathrm{~kJ} \mathrm{~mol}^{-1}$.

The comparison between electrocatalytic and photocatalytic studies [106] shows very strong correlation that the improvement in electrocatalysis leads to similar improvement in photocatalysis. Both electrocatalytic and photocatalytic systems have similar dependence on $\mathrm{pH}$ change, where high rates were observed for higher $\mathrm{pH}$. The $\mathrm{pH}$ dependence is associated with electrocatalytic kinetics that accordingly influenced the photocatalytic rates. Furthermore, the difference in apparent activation energies for both systems is associated with the possible effects of

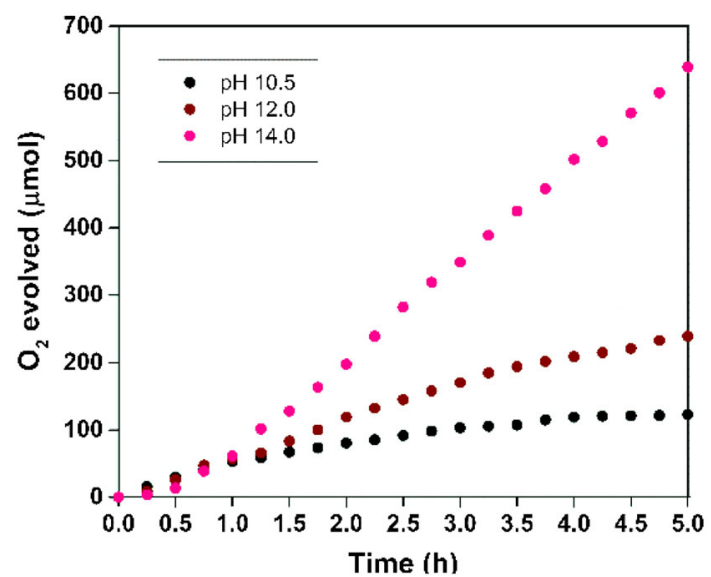

Fig. 10 Time course of photocatalytic OER on $\mathrm{CoO}_{\mathrm{x}} / \mathrm{Ta}_{3} \mathrm{~N}_{5} \cdot(0.1 \mathrm{M}$ $\mathrm{Na}_{2} \mathrm{~S}_{2} \mathrm{O}_{8}$, at $\mathrm{pH} 10.5,12.0$ or 14.0 adjusted with $\mathrm{NaOH}$, under visible light irradiation $(420<\lambda<800 \mathrm{~nm}))$

temperature on the individual thermodynamic and kinetic parameters of the reaction process.

\section{Future directions}

Developing efficient visible-light-responsive photocatalysts is essential for making the photocatalytic overall water splitting reaction economically competitive for hydrogen production. To achieve this goal, all the parameters involved in photocatalytic water splitting should be optimized. A collection of theoretical and experimental studies of properties associated with $\mathrm{Ta}_{3} \mathrm{~N}_{5}$ have been utilized to obtain a comprehensive understanding of this material. The fundamental structural and optoelectronic properties of $\mathrm{Ta}_{3} \mathrm{~N}_{5}$ have been addressed. The nitridation is confirmed to proceed via the successive transformation of $\mathrm{Ta}_{2} \mathrm{O}_{5} \mathrm{TaON} \mathrm{Ta}_{3} \mathrm{~N}_{5}$ on the basis of XRD patterns and Rietveld analysis. From the electronic properties, the dielectric constant and effective masses have been calculated. Because of its high dielectric constant and relatively low effective masses, $\mathrm{Ta}_{3} \mathrm{~N}_{5}$ is promising for photocatalytic reaction applications. Studies of lattice dynamics, optical properties, and band positions have been able to clearly show that the synthesized $\mathrm{Ta}_{3} \mathrm{~N}_{5}$ is essentially defective and non-stoichiometric and that a truly pure phase of $\mathrm{Ta}_{3} \mathrm{~N}_{5}$ has never been achieved, even though XRD has shown a pure phase sample. The photophysical properties of $\mathrm{Ta}_{3} \mathrm{~N}_{5}$, such as the absorption coefficient, carrier mobility, and carrier lifetime, have been experimentally measured by synthesizing $\mathrm{Ta}_{3} \mathrm{~N}_{5}$ thin films. Very low kinetic properties with very low transport properties and fast carrier recombination explained why overall water splitting has never been achieved with $\mathrm{Ta}_{3} \mathrm{~N}_{5}$ as a 
photocatalyst to date. A surface modification with a cocatalyst and new interface construction are thus suggested to improve the photocatalytic activity. The extent to which the surface states of $\mathrm{Ta}_{3} \mathrm{~N}_{5}$ photocatalysts affect photocatalytic performance has been investigated. The surface topmost layer is demonstrated to play a critical role in the photocatalytic activity of $\mathrm{Ta}_{3} \mathrm{~N}_{5}$; further research on the surface properties of $\mathrm{Ta}_{3} \mathrm{~N}_{5}$ should be conducted to understand and improve charge separation and the resulting photocatalytic activity. Finally, a remarkable improvement in the photocatalytic OER has been achieved with the addition of cobalt as a cocatalyst. There is a trade-off between the optimum contact of hole transfer from bulk $\mathrm{Ta}_{3} \mathrm{~N}_{5}$ to the surface of the cobalt cocatalyst and providing active sites for the electrochemical reaction. Knowing the characteristics of cobalt on the $\mathrm{Ta}_{3} \mathrm{~N}_{5}$ surface, further improvement was attempted by adding a noble metal to the $\mathrm{CoO}_{\mathrm{x}} / \mathrm{Ta}_{3} \mathrm{~N}_{5}$ photocatalyst system, where a synergetic effect of $\mathrm{CoO}_{\mathrm{x}}$ and noble metals was observed. Although a solar energy to hydrogen conversion efficiency of greater than $1 \%$ using $\mathrm{Ta}_{3} \mathrm{~N}_{5}$ has been achieved, substantial bias in the PEC configuration or the use of a sacrificial reagent is still mandatory. As mentioned in the beginning of this part, the main limitation for $\mathrm{Ta}_{3} \mathrm{~N}_{5}$ is that we cannot make it until now chemically stoichiometric and without crystalline defects. The ammonia treatment necessary for the production of $\mathrm{Ta}_{3} \mathrm{~N}_{5}$ is an aggressive treatment and induces many defects in the crystalline structure that act as sites of charge carrier recombination in the material. Developing new synthesis techniques or new in situ methods of the growth control for $\mathrm{Ta}_{3} \mathrm{~N}_{5}$ is predicted to be able to produce better chemical stoichiometry and improve the crystalline structuration of the material (like epitaxial growth). It can be a key to overcome the $\mathrm{Ta}_{3} \mathrm{~N}_{5}$ limitations and make it efficient for overall water splitting. On the other hand, developing efficient cocatalysts with new deposition techniques for surface functionalization can help to improve the photocatalytic efficiency of $\mathrm{Ta}_{3} \mathrm{~N}_{5}$. Research should continue as the efficiency has not yet reached the desired level. However, a thorough understanding of all the processes involved in the photocatalytic process would pin down the crucial parameters, which will lead to the design of photocatalysts for solving targeted problems.

Open Access This article is distributed under the terms of the Creative Commons Attribution 4.0 International License (http:// creativecommons.org/licenses/by/4.0/), which permits unrestricted use, distribution, and reproduction in any medium, provided you give appropriate credit to the original author(s) and the source, provide a link to the Creative Commons license, and indicate if changes were made.

\section{References}

1. Bard, A., Fox, M.A.: Artificial photosynthesis: solar splitting of water to hydrogen and oxygen. Acc. Chem. Res. 28, 141-145 (1995). doi:10.1021/ar00051a007

2. Khaselev, O., Turner, J.A.: Monolithic photovoltaic-photoelectrochemical device for hydrogen production via water splitting. Science. 280, 425-427 (1998). doi:10.1126/science.280.5362. 425

3. Grätzel, M.: Photoelectrochemical cells. Nature 414, 338-344 (2001). doi: $10.1038 / 35104607$

4. Walter, M.G., Warren, E., McKone, J., Boettcher, S., Mi, Q., Santori, E., Lewis, N.: Solar water splitting cells. Chem. Rev. 110, 6446-6473 (2010). doi:10.1021/cr1002326

5. Nocera, D.: The artificial leaf. Acc. Chem. Res. 45, 767-776 (2012). doi:10.1021/ar2003013

6. Ismail, A.A., Bahnemann, D.W.: Photochemical splitting of water for hydrogen production by photocatalysis. Solar Energy Mater. Solar Cells. 128, 85-101 (2014). doi: 10.1016/j.solmat. 2014.04.037

7. Takanabe, K., Domen, K.: Toward visible light response: overall water splitting using heterogeneous photocatalysts. Green 1, 313-322 (2011). doi:10.1515/GREEN.2011.030

8. Takanabe, K., Domen, K.: Preparation of inorganic photocatalytic materials for overall water splitting. Chemcatchem. 4, 1485-1497 (2012). doi:10.1002/cctc.201200324

9. Fujishima, A., Honda, K.: Electrochemical photolysis of water at a semiconductor electrode. Nature 238, 37-38 (1972). doi:10. $1038 / 238037 \mathrm{a} 0$

10. Sivula, K., Le Formal, F., Gratzel, M.: Solar water splitting: progress using hematite $\left(\alpha-\mathrm{Fe}_{2} \mathrm{O}_{3}\right)$ photoelectrodes. Chemsuschem 4, 432 (2011). doi:10.1002/cssc.201000416

11. Barroso, M., Mesa, C.A., Pendlebury, S.R., CowanAJ, Hisatomi T., Sivula, K., Grätzel, M., Klug, D.R., Durrant, J.R.: Dynamics of photogenerated holes in surface modified $\alpha-\mathrm{Fe}_{2} \mathrm{O}_{3}$ photoanodes for solar water splitting. PNAS 109, 5640 (2012). doi:10. 1073/pnas.1118326109

12. Abdi, F.F., Han, L., Smets, A., Zeman, M., Dam, B., van de Krol, R.: Efficient solar water splitting by enhanced charge separation in a bismuth vanadate-silicon tandem photoelectrode. Nat. Commun. 4, 2195 (2013). doi:10.1038/ncomms3195

13. Kim, T.W., Choi, K.-S.: Nanoporous $\mathrm{BiVO}_{4}$ photoanodes with dual-layer oxygen evolution catalysts for solar water splitting. Science 343, 990 (2014). doi:10.1126/science.1246913

14. Solarska, R., Jurczakowski, R., Augustynski, J.: A highly stable, efficient visible-light driven water photoelectrolysis system using a nanocrystalline $\mathrm{WO}_{3}$ photoanode and a methane sulfonic acid electrolyte. Nanoscale 4, 1553 (2012). doi:10.1039/ c2nr11573e

15. Seabold, J.A., Choi, K.S.: Effect of a cobalt-based oxygen evolution catalyst on the stability and the selectivity of photooxidation reactions of a $\mathrm{WO}_{3}$ photoanode. Chem. Mater. 23, 1105-1112 (2011). doi:10.1021/cm1019469

16. Higashi, M., Domen, K., Abe, R.: Highly stable water splitting on oxynitride $\mathrm{TaON}$ photoanode system under visible light irradiation. J. Am. Chem. Soc. 13, 46968 (2012). doi:10.1021/ ja302059g

17. Kubota, J., Domen, K.: Photocatalytic water splitting using oxynitride and nitride semiconductor powders for production of solar hydrogen. Electrochem. Soc. Interface Summer, 22(2), 57-62 (2013). doi: 10.1149/2.F07132if

18. Maeda, K., Domen, K.: New non-oxide photocatalysts designed for overall water splitting under visible light. J. Phys. Chem. C 111, 7851-7861 (2007). doi:10.1021/jp070911w 
19. Chun, W.J., Ishikawa, A., Fujisawa, H., Takata, T., Kondo, J.N., Hara, M., Kawai, M., Matsumoto, Y., Domen, K.: Conduction and valence band positions of $\mathrm{Ta}_{2} \mathrm{O}_{5}, \mathrm{TaON}$, and $\mathrm{Ta}_{3} \mathrm{~N}_{5}$ by UPS and electrochemical methods. J. Phys. Chem. B 107, 1798-1803 (2003). doi:10.1021/jp027593f

20. Li, Y., Takata, T., Cha, D., Takanabe, K., Minegishi, T., Kubota, J., Domen, K.: Vertically aligned $\mathrm{Ta}_{3} \mathrm{~N}_{5}$ nanorod arrays for solar-driven photoelectrochemical water splitting. Adv. Mater. 25, 125-131 (2013). doi:10.1002/adma.201202582

21. Li, Y., Zhang, L., Torres-Pardo, A., Gonzalez-Calbet, J.M., Ma, Y., Oleynikov, P., Terasaki, O., Asahina, S., Shima, M., Cha, D., Zhao, L., Takanabe, K., Kubota, J., Domen, K.: Cobalt phosphate-modified barium-doped tantalum nitride nanorod photoanode with $1.5 \%$ solar energy conversion efficiency. Nat. Commun. (2013). doi:10.1038/ncomms3566

22. Gao, R., Hu, L., Chen, M., Wu, L.: Controllable fabrication and photoelectrochemical property of multilayer tantalum nitride hollow sphere-nanofilms. Small 10, 3038-3044 (2014). doi:10. 1002/smll.201303873

23. Liu, G., Shi, J., Zhang, F., Chen, Z., Han, J., Ding, C., Chen, S., Wang, Z., Han, H., Li, C.A.: Tantalum nitride photoanode modified with a hole-storage layer for highly stable solar water splitting. Angew. Chem. Int. Ed. 53, 7295 (2014). doi:10.1002/ anie. 201404697

24. Cong, Y., Park, H.S., Dang, H.X., Fan, F.-R.F., Bard, A.J., Mullins, C.B.: Tantalum cobalt nitride photocatalysts for water oxidation under visible light. Chem. Mater. 24, 579-586 (2012). doi:10.1021/cm203269n

25. Tong, H., Ouyang, S., Bi, Y., Umezawa, N., Oshikiri, M., Ye, J.: Nano-photocatalytic materials: possibilities and challenges. J. Adv. Mater. 24, 229-251 (2012). doi:10.1002/adma. 201102752

26. Takanabe, K.: Solar water splitting using semiconductor photocatalyst powders. Top Curr. Chem. (2015). doi:10.1007/128_ 2015_646. (In press)

27. Maeda, K., Domen, K.: Photocatalytic water splitting: recent progress and future challenges. J. Phys. Chem. Lett. 1, 2655-2661 (2010). doi:10.1021/jz1007966

28. Kudo, A., Miseki, Y.: Heterogeneous photocatalyst materials for water splitting. Chem. Soc. Rev. 38, 253-278 (2009). doi:10. 1039/B800489G

29. Abe, R.: Recent progress on photocatalytic and photoelectrochemical water splitting under visible light irradiation. J. Photochem. Photobiol. C 11, 179-209 (2010). doi:10.1016/j. jphotochemrev.2011.02.003

30. Osterloh, F.E.: Inorganic materials as catalysts for photochemical splitting of water. Chem. Mater. 20, 35 (2008). doi:10.1021/ cm7024203

31. Osterloh, F.E.: Inorganic nanostructures for photoelectrochemical and photocatalytic water splitting. Chem. Soc. Rev. 42, 2294-2320 (2013). doi:10.1039/c2cs35266d

32. Kakuta, N., Park, K.H., Finlayson, M.F., Ueno, A., Bard, A.J., Campion, A., Fox, M.A., Webber, S.E., White, J.M.: Photoassisted hydrogen production using visible light and coprecipitated ZnS.CdS without a noble metal. J. Phys. Chem. 89, 732-734 (1985). doi:10.1016/j.solmat.2014.04.037

33. Reber, J.F., Rusek, M.: Photochemical hydrogen production with platinized suspensions of cadmium sulfide and cadmium zinc sulfide modified by silver sulfide. J. Phys. Chem. 90, 824 (1985). doi:10.1021/j100251a002

34. Xing, C., Zhang, V., Yan, W., Guo, L.: Band structure-controlled solid solution of $\mathrm{Cd}_{1-\mathrm{x}} \mathrm{Zn}_{\mathrm{x}} \mathrm{S}$ photocatalyst for hydrogen production by water splitting. Int. J. Hydrog. Energy 31, 2018 (2006). doi:10.1016/j.ijhydene.2006.02.003

35. Bao, N., Shen, L., Takata, T., Domen, K.: Self-templated synthesis of nanoporous CdS nanostructures for highly efficient photocatalytic hydrogen production under visible light. Chem. Mater. 20, 110 (2008). doi:10.1021/cm7029344

36. Matsumura, M., Saho, Y., Tsubomura, H.: Photocatalytic hydrogen production from solutions of sulfite using platinized cadmium sulfide powder. J. Phys. Chem. 87(20), 3807-3808 (1983). doi:10.1021/j100243a005

37. Darwent, J.R., Mills, A.: Photo-oxidation of water sensitized by $\mathrm{WO}_{3}$ powder. J. Chem. Soc. Faraday Trans. 78(2), 359-367 (1982). doi:10.1039/F29827800359

38. Erbs, W., Desilvestro, J., Borgarello, E., Gratzel, M.: Visiblelight-induced oxygen generation from aqueous dispersions of tungsten(VI) oxide. J. Phys. Chem. 88, 4001-4006 (1984). doi:10.1021/j150662a028

39. Hara, M., Hitoki, G., Takata, T., Kondo, J.N., Kobayashi, H., Domen, K.: TaON and $\mathrm{Ta}_{3} \mathrm{~N}_{5}$ as new visible light driven photocatalysts. Catal. Today 78, 555-560 (2003). doi:10.1016/ S0920-5861(02)00354-1

40. Hitoki, G., Ishikawa, A., Takata, T., Kondo, J.N., Hara, M., Domen, K.: $\mathrm{Ta}_{3} \mathrm{~N}_{5}$ as a novel visible light-driven photocatalyst $(\lambda<600 \mathrm{~nm})$. Chem. Lett. 7, 736-737 (2002). doi:10.1246/cl. 2002.736

41. Ziani, A., Nurlaela, E., Dhawale, D.S., Silva, D.A., Alarousu, E., Mohammed, O.F., Takanabe, K.: Carrier dynamics of a visiblelight responsive $\mathrm{Ta}_{3} \mathrm{~N}_{5}$ photoanode for water oxidation. Phys. Chem. Chem. Phys. 17, 2670-2677 (2015). doi:10.1039/ $\mathrm{c} 4 \mathrm{cp} 05616 \mathrm{~g}$

42. Ma, S.S.K., Hisatomi, T., Maeda, K., Moriya, Y., Domen, K.: Enhanced water oxidation on $\mathrm{Ta}_{3} \mathrm{~N}_{5}$ photocatalysts by modification with alkaline metal salts. J. Am. Chem. Soc. 134, 19993-19996 (2012). doi:10.1021/ja3095747

43. Nurlaela, E., Ould-Chikh, S., Harb, M., del Gobbo, S., Aouine, M., Puzenat, E., Sautet, P., Domen, K., Basset, J.-M., Takanabe, $\mathrm{K}$.: Critical role of the semiconductor-electrolyte interface in photocatalytic performance for water-splitting reactions using $\mathrm{Ta}_{3} \mathrm{~N}_{5}$ particles. Chem. Mater. 26, 4812-4825 (2014). doi:10. $1021 / \mathrm{cm} 502015 \mathrm{q}$

44. Harb, M., Sautet, P., Nurlaela, E., Raybaud, P., Cavallo, L., Domen, K., Basset, J.-M., Takanabe, K.: Tuning the properties of visible-light-responsive tantalum (oxy)nitride photocatalysts by non-stoichiometric compositions: a first-principle viewpoint. Phys. Chem. Chem. Phy. 16, 20548-20560 (2014). doi:10.1039/ c4cp03594a

45. Yuliati, L., Yang, J.H., Wang, X., Maeda, K., Takata, T., Antonietti, M., Domen, K.: Highly active $\operatorname{tantalum}(\mathrm{V})$ nitride nanoparticles prepared from a mesoporous carbon nitride template for photocatalytic hydrogen evolution under visible lght irradiation. J. Mater. Chem. 20, 4295-4298 (2010). doi:10.1039/ C0JM00341G

46. Fukasawa, Y., Takanabe, K., Shimojima, A., Antonietti, M., Domen, K., Okubo, T.: Synthesis of ordered porous graphitic$\mathrm{C}_{3} \mathrm{~N}_{4}$ and regularly arranged $\mathrm{Ta}_{3} \mathrm{~N}_{5}$ nanoparticles by using selfassembled silica nanospheres as a primary template. Chem. Asian J. 6, 103-109 (2011). doi:10.1002/asia.201000523

47. Liu, X., Zhao, L., Domen, K., Takanabe, K.: Photocatalytic hydrogen production using visible-light-responsive $\mathrm{Ta}_{3} \mathrm{~N}_{5}$ photocatalyst supported on monodisperse spherical $\mathrm{SiO}_{2}$ particulates. Mater. Res. Bull. 49, 58-65 (2014). doi:10.1016/j. materresbull.2013.08.069

48. Hara, M., Chiba, E., Ishikawa, A., Takata, T., Kondo, J.N., Domen, K.: $\mathrm{Ta}_{3} \mathrm{~N}_{5}$ and $\mathrm{TaON}$ thin films on Ta foil: surface composition and stability. J. Phys. Chem. B 107, 13441-13445 (2003). doi:10.1021/jp036189t

49. Ishikawa, A., Takata, T., Kondo, J.N., Hara, M., Domen, K.: Electrochemical behavior of thin $\mathrm{Ta}_{3} \mathrm{~N}_{5}$ semiconductor film. J. Phys. Chem. B 108, 11049-11053 (2004). doi:10.1021/ jp048802u 
50. Li, M., Luo, W., Cao, D., Zhao, X., Li, Z., Yu, T., Zou, Z.: A Co-catalyst-loaded $\mathrm{Ta}_{3} \mathrm{~N}_{5}$ photoanode with a high solar photocurrent for water splitting upon facile removal of the surface layer. Angew. Chem. Int. Ed. 52, 11016-11020 (2013). doi:10. 1002/anie. 201305350

51. Armytage, D., Fender, B.E.F.: Anion ordering in TaON: a powder neutron-diffraction investigation. Acta Cryst. Sect. B 30(3), 809-812 (1974). doi:10.1107/S0567740874003761

52. Dabirian, A., van de Krol, R.: High-temperature ammonolysis of thin film $\mathrm{Ta}_{2} \mathrm{O}_{5}$ photoanodes evolution of structural, optical, and photoelectrochemical properties. Chem. Mater. 27, 708-715 (2015). doi:10.1021/cm503215p

53. Reuter, K., Scheffler, M.: Composition, structure, and stability of $\mathrm{RuO}_{2}(110)$ as a function of oxygen pressure. Phys. Rev. B 65, 035406 (2001). doi:10.1103/PhysRevB.65.035406

54. Reuter, K., Scheffler, M.: Composition and structure of the $\mathrm{RuO}_{2}$ (110) surface in an $\mathrm{O}_{2}$ and $\mathrm{CO}$ environment: implications for the catalytic formation of $\mathrm{CO}_{2}$. Phys. Rev. B 68, 045407 (2003). doi:10.1103/PhysRevB.68.045407

55. Henderson, S.J., Hector, A.L.: Structural and compositional variations in $\mathrm{Ta}_{3} \mathrm{~N}_{5}$ produced by high temperature ammonolysis of tantalum oxide. J. Solid State Chem. 179, 3518-3524 (2006). doi:10.1016/j.jssc.2006.07.021

56. Brus, L.E.J.: A simple model for the ionization potential, electron affinity, and aqueous redox potentials of small semiconductor crystallites. J. Chem. Phys. 79, 5566-5571 (1983). doi:10.1063/1.445676

57. Ekimov, A.I., Onushchenko, A.A.: Size quantization of the electron energy spectrum in a microscopic semiconductor crystal. JETP Lett. 40, 1136-1139 (1984)

58. Ho, C.-H., Ke-B, Low, Klie, R.F., Maeda, K., Domen, K., Meyer, R.J., Snee, P.T.: Synthesis and characterization of semiconductor tantalum nitride nanoparticles. J. Phys. Chem. C 115, 647-652 (2011). doi:10.1021/jp110105u

59. Gao, Q., Wang, S., Ma, Y., Tang, Y., Giordano, C., Antonietti, M.: $\mathrm{SiO}_{2}$-surface-assisted controllable synthesis of $\mathrm{TaON}$ and $\mathrm{Ta}_{3} \mathrm{~N}_{5}$ nanoparticles for alkene epoxidation. Angew. Chem. Int. Ed. 51, 961-965 (2012). doi:10.1002/anie.201107216

60. Pinaud, B.A., Vesborg, P.C.K., Jaramillo, T.F.: Effect of film morphology and thickness on charge transport in $\mathrm{Ta}_{3} \mathrm{~N}_{5} / \mathrm{Ta}$ photoanodes for solar water splitting. J. Phys. Chem. C 116, 15918-15924 (2012). doi:10.1021/jp3041742

61. Feng, X., La Tempa, T., Basham, J., Mor, G., Varghese, O., Grimes, C.: $\mathrm{Ta}_{3} \mathrm{~N}_{5}$ nanotube arrays for visible light water photoelectrolysis. Nano Lett. 10, 948-952 (2010). doi:10.1021/ nl903886e

62. Yokoyama, D., Hashiguchi, H., Maeda, K., Minegishi, T., Takata, T., Abe, R., Kubota, J., Domen, K.: $\mathrm{Ta}_{3} \mathrm{~N}_{5}$ photoanodes for water splitting prepared by sputtering. Thin Solid Films $\mathbf{5 1 9}$, 2087-2092 (2011). doi:10.1016/j.tsf.2010.10.055

63. Brese, N., O'Keeffe, M.: The structure of $\mathrm{Ta}_{3} \mathrm{~N}_{5}$ at $16 \mathrm{~K}$ by time-of-flight neutron diffraction. Acta Cryst. C 47, 2291-2294 (1991)

64. Nurlaela, E., Harb, M., del Gobbo, S., Vashishta, M., Takanabe, K.: Combined experimental and theoretical assessments of the lattice dynamics and optoelectronics of $\mathrm{TaON}$ and $\mathrm{Ta}_{3} \mathrm{~N}_{5}$. J. Solid State Chem. 229, 219-227 (2015). doi:10.1016/j.jssc. 2015.06.029

65. Gajdoš, M., Hummer, K., Kresse, G., Furthmüller, J., Bechstedt, F.: Linear optical properties in the projector-augmented wave methodology. Rev. B, Phys (2006). doi:10.1103/PhysRevB.73. 045112

66. Le Bahers, T., Rérat, M., Sautet, P.: Semiconductors used in photovoltaic and photocatalytic devices: assessing fundamental properties from DFT. J. Phys. Chem. C 118, 5997-6008 (2014)
67. Morbec, J.M., Narkeviciute, I., Jaramillo, T.F., Galli, G.: Optoelectronic properties of $\mathrm{Ta}_{3} \mathrm{~N}_{5}$ : a joint theoretical and experimental study. Phys. Rev. B 90, 155204 (2014). doi:10. 1103/PhysRevB.90.155204

68. Watanabe, E., Ushiyama, H., Yamashita, K.: Theoretical studies on the stabilities and reactivities of $\mathrm{Ta}_{3} \mathrm{~N}_{5}\left(\begin{array}{lll}1 & 0 & 0\end{array}\right)$ surfaces. Chem. Phys. Lett. 561-562, 57-62 (2013). doi:10.1016/j.cplett. 2012.12.068

69. Wang, J., Feng, J., Zhang, L., Li, Z., Zou, Z.: Role of oxygen impurity on the mechanical stability and atomic cohesion of $\mathrm{Ta}_{3} \mathrm{~N}_{5}$ semiconductor photocatalyst. Phys. Chem. Chem. Phys. 16, 15375 (2014). doi:10.1039/C4CP00120F

70. Wang, J., Fang, T., Zhang, L., Feng, J., Li, Z., Zou, Z.: Effects of oxygen doping on optical band gap and band edge positions of $\mathrm{Ta}_{3} \mathrm{~N}_{5}$ photocatalyst: A GGA + U calculation. J. Catal. 309, 291-299 (2014). doi:10.1016/j.jcat.2013.10.014

71. Lacomba-Perales, R., Martinez-García, D., Errandonea, D., Le Godec, Y., Philippe, J., Le Marchand, G., Chervin, J.C., Polian, A., Múñoz, A., López-Solano, : Experimental and theoretical investigation of the stability of the monoclinic BaWO4-II phase at high pressure and high temperature. J. Phys. Rev. B 8, 144117 (2010)

72. Quarti, C., Grancini, G., Mosconi, E., Bruno, P., Ball, J.M., Lee, M.M., Snaith, H.J., Petrozza, A.M., Angelis, F.D.: The Raman spectrum of the $\mathrm{CH}_{3} \mathrm{NH}_{3} \mathrm{PbI}_{3}$ hybrid perovskite: interplay of theory and experiment. J. Phys. Chem. Lett. 5, 279-284 (2014)

73. Dabirian, A., Van de Krol, R.: Resonant optical absorption and defect control in $\mathrm{Ta}_{3} \mathrm{~N}_{5}$ photoanodes. Appl. Phys. Lett. 102, 033905 (2013). doi:10.1063/1.4788930

74. Harb, M., Cavallo, L., Basset, J.-M.: Major difference in visiblelight photocatalytic features between perfect and self-defective $\mathrm{Ta}_{3} \mathrm{~N}_{5}$ materials a screened coulomb hybrid DFT investigation. J. Phys. Chem. C 118, 20784-20790 (2014). doi:10.1021/ jp506066p

75. Khan, S., Zapata, M.J.M., Preira, M.B., Gonçalves, R.V., Strizik, L., Dupont, J., Santos, M.J.L., Teixeira, S.R.: Structural, optical and photoelectrochemical characterizations of monoclinic $\mathrm{Ta}_{3} \mathrm{~N}_{5}$ thin films. Phys. Chem. Chem. Phys. Accept. (2015). doi:10.1039/x0xx00000x

76. Inoue, Y.: Photocatalytic water splitting by $\mathrm{RuO}_{2}$-loaded metal oxides and nitrides with $\mathrm{d}^{0}$ - and $\mathrm{d}^{10^{\circ}}$-related electronic configurations. Energy Environ. Sci. 2, 364 (2009). doi:10.1039/ B816677N

77. Reshak, A.H.: Electronic structure and dispersion of optical function of tantalum nitride as a visible light photo-catalyst. Comp. Mater. Sci. 89, 45 (2014). doi:10.1016/j.commatsci.2014. 03.035

78. El-Nahass, M.M., Youssef, T.E.: Influence of X-ray irradiation on the optical properties of ruthenium(II)octa-(n-hexyl)-phthalocyanine thin film. J. Alloys Compd 503, 86-91 (2010). doi:10.1016/j.jallcom.2010.04.029

79. Vurgaftman, I., Meyer, J.R., Ram-Mohan, L.R.: Band parameters for III-V compounds semiconductors and their alloys. J. Appl. Phys. 89, 5815-5875 (2001). doi:10.1063/1.1368156

80. Taguchi, T., Shirafuji, J., Inuishi, Y.: Excitonic emission in cadmium telluride. Phys. Status Solidi B 68, 727-738 (1975). doi: $10.1002 / \mathrm{pssb} .2220680234$

81. Young, K.F., Frederikse, H.P.R.: Compilation of static dielectric constant of inorganics solids. J. Phys. Chem. Ref. Data 409, 2313 (1973)

82. Gilleo, M.A., Bailey, P.T., Hill, D.E.: Free-carrier and exciton recombination radiation in GaAs. Phys. Rev. 174, 898-905 (1968). doi:10.1103/PhysRev.174.898

83. Madelung, O.: Semiconductors: data handbook, 3rd edn. Springer, New York (2004) 
84. Adashi, S.: GaAs and related materials. World Scientific Publishing Co. Pte. Ltd, Singapore (1994)

85. Zeiri, L., Patla, I., Acharya, S., Golan, Y., Efrima, S.: Raman spectroscopy of ultranarrow CdS nanostructures. J. Phys. Chem. C 111, 11843-11848 (2007). doi:10.1021/jp072015q

86. Furube A, Maeda K, Domen K Transient absorption study on photogenerated carrier dynamics invisible light responsive photocatalysts GaN:ZnO. Proc of SPIE 20118109810904

87. Chen, Z., Jaramillo, T.F., Deutsch, T.G., Kleiman-Shwarsctein, A., Forman, A.J., Gaillard, N., Garland, R., Takanabe, K., Heske, C., Sunkara, M., McFarland, E.W., Domen, K., Miller, E.L., Turner, J.A., Dinh, H.N.: Accelerating materials development for photoelectrochemical hydrogen production: standards for methods, definitions, and reporting protocols. J. Mater. Res. 25, 3-16 (2010). doi:10.1557/JMR.2010.0020

88. Esswein, A.J., McMurdo, M.J., Ross, P.N., Bell, A.T., Tilley, T.D.: Size-dependent activity of $\mathrm{Co}_{3} \mathrm{O}_{4}$ nanoparticle anodes for alkaline water electrolysis. J. Phys. Chem. C 113, 15068-15072 (2009). doi:10.1021/jp904022e

89. Gorlin, Y., Chung, C.-J., Nordlund, D., Clemens, B.M.: Electrocatalytic oxygen evolution reaction (OER) on $\mathrm{Ru}, \mathrm{Ir}$, and $\mathrm{Pt}$ catalysts: a comparative study of nanoparticles and bulk materials. ACS Catal. 2, 1765-1772 (2012). doi:10.1021/cs3003098

90. Deng, X., Tüysüz, H.: Cobalt-oxide-based materials as water oxidation catalyst: recent progress and challenges. ACS Catal. 4, 3701-3714 (2014). doi:10.1021/cs500713d

91. Yeo, B.S., Bell, A.T.: Enhanced activity of gold-supported cobalt oxide for the electrochemical evolution of oxygen. J. Am. Chem. Soc. 133, 5587-5593 (2011). doi:10.1021/ja200559j

92. Liao, M., Feng, J., Luo, W., Wang, Z., Zhang, J., Li, Z., Yu, T., Zou, Z.: $\mathrm{Co}_{3} \mathrm{O}_{4}$ nanoparticles as robust water oxidation catalysts towards remarkably enhanced photostability of a $\mathrm{Ta}_{3} \mathrm{~N}_{5}$ photoanode. Adv. Funct. Mater. 22, 3066-3074 (2012). doi:10. 1002/adfm.201102966

93. Kasahara, A., Nukumizu, K., Hitoki, G., Takata, T., Kondo, J.N., Hara, M., Kobayashi, H., Domen, K.: Photoreactions on $\mathrm{LaTiO}_{2} \mathrm{~N}$ under visible light irradiation. J. Phys. Chem. A 106, 6750-6753 (2002). doi:10.1021/jp025961

94. Higashi, M., Domen, K., Abe, R.: Fabrication of an efficient $\mathrm{BaTaO}_{2} \mathrm{~N}$ photoanode harvesting a wide range of visible light for water splitting. J. Am. Chem. Soc. 135, 10238-10241 (2013). doi:10.1021/ja404030x

95. Ran, J., Zhang, J., Yu, J., Jaroniecc, M., Qiao, S.Z.: Earthabundant cocatalysts for semiconductor based photocatalytic water splitting. Chem. Soc. Rev. 43, 7787-7812 (2014). doi:10. $1039 / \mathrm{c} 3 \operatorname{cs} 60425 \mathrm{j}$
96. Zhong, D.K., Choi, S., Gamelin, D.R.: Near-complete suppression of surface recombination in solar photoelectrolysis by "CoPi" catalyst-modified W:biVO 4 . J. Am. Chem. Soc. 133, 18370-18377 (2011). doi:10.1021/ja207348x

97. Barroso, M., Cowan, A.J., Pendlebury, S.R., Gratzel, M., Klug, D.R., Durrant, J.R.: The role of cobalt phosphate in enhancing the photocatalytic activity of $\alpha-\mathrm{Fe}_{2} \mathrm{O}_{3}$ toward water oxidation. J. Am. Chem. Soc. 1331, 4868-14871 (2011). doi:10.1021/ ja205325v

98. Long, M., Cai, W., Kisch, H.: Visible light induced photoelectrochemical properties of $\mathrm{n}-\mathrm{BiVO}_{4}$ and $\mathrm{n}-\mathrm{BiVO} / \mathrm{p}-\mathrm{Co}_{3} \mathrm{O}_{4}$. J. Phys. Chem. C 112, 548-554 (2008). doi:10.1021/jp075605x

99. Nurlaela, E., Ould-Chikh, S., Llorens, I., Hazemann, JL., Takanabe, K.: Establishing efficient cobalt based catalytic sites for oxygen evolution on $\mathrm{Ta}_{3} \mathrm{~N}_{5}$ photocatalyst. Chem. Mater. 27, 5685-5694 (2015). doi:10.1021/acs.chemmater.5b02139

100. Shinagawa, T., Takanabe, K.: Identification of intrinsic catalytic activity for electrochemical reduction of water molecules to generate hydrogen. Phys. Chem. Chem. Phys. 17, 15111-15114 (2015). doi:10.1039/c5cp02330k

101. Shinagawa, T., Takanabe, K.: Electrocatalytic hydrogen evolution under densely buffered neutral $\mathrm{pH}$ conditions. J. Phys. Chem. C 119, 20453-20458 (2015). doi:10.1021/acs.jpcc. 5 b05295

102. Shinagawa, T., Takanabe, K.: Impact of solute concentration on the electrocatalytic conversion of dissolved gases in buffered solutions. J. Power Sources 287, 465-471 (2015). doi:10.1016/j. jpowsour.2015.04.091

103. Abdi, F., Savenije, T., May, M., Dam, B., van de Krol, R.: The origin of slow carrier transport in $\mathrm{BiVO}_{4}$ thin film photoanodes: a time-resolved microwave conductivity study. J. Phys. Chem. Lett. 4, 2752 (2013). doi:10.1021/jz4013257

104. Joly, A.G., Williams, J.R., Chambers, S.A., Xiong, G., Hess, W.P., Laman, D.M.: Carrier dynamics in $\alpha-\mathrm{Fe} 2 \mathrm{O} 3$ (0001) thin films and single crystals probed by femtosecond transient absorption and reflectivity. J. Appl. Phys. 99, 053521 (2006). doi:10.1063/1.2177426

105. Shinde, S.S., Bansode, R.A., Bhosale, C.H., Rajpure, K.Y.: Physical properties of hematite $\alpha-\mathrm{Fe}_{2} \mathrm{O}_{3}$ thin films: application to photoelectrochemical solar cells. J. Semicond. 32, 013001 (2011). doi:10.1088/1674-4926/32/1/013001

106. Nurlaela, E., Shinagawa, T., Qureshi, M., Dhawale, D.S., Takanabe, K.: Temperature dependence of electrocatalytic and photocatalytic oxygen evolution reaction rates using $\mathrm{NiFe}$ oxide. ACS Catal. 6, 1713 (2016). doi:10.1021/acscatal.5b02804 